\title{
Revisão sistemática de estudos de avaliação de tecnologias educacionais para letramento e alfabetização de estudantes com Transtornos do Neurodesenvolvimento no contexto brasileiro
}

\author{
Title: Systematic Review of studies assessing the use of educational technology to literacy of \\ students with Neurodevelopmental Disorders in the Brazilian context
}

\section{Julia Zanetti Rocca}

Professora da Universidade Federal de Rondonópolis (UFR) e do Programa de Pós-graduação em Psicologia da Universidade Federal de Mato Grosso (UFMT) redxgv@gmail.com

\author{
Luiz Alexandre Barbosa de Freitas \\ Doutorando em Teoria e Pesquisa do \\ Comportamento na Universidade \\ Federal do Pará (UFPA) e professor \\ no Departamento de Psicologia da \\ Universidade Federal de Mato \\ Grosso (UFMT) \\ luizfreitas@ufmt.br
}

Ricardo Fernandes Campos Jr. Doutorando no Instituto de Ciências Matemáticas e de Computação (ICMC) pela Universidade de São Paulo (USP), é mestre em Genética pela Universidade de São Paulo (USP), e graduado em Ciências Biológicas pela Universidade Federal de Mato Grosso (UFMT) ricardofcj@gmail.com

\author{
Lissa Carvalho de Souza \\ Graduanda em Psicologia pela \\ Universidade Federal de \\ Rondonópolis (UFR) \\ lissacarvalhosouza@gmail.com
}

\author{
Giovanna Rebouças Rodrigues \\ Martins \\ Graduanda em Psicologia pela \\ Universidade Federal de \\ Rondonópolis (UFR); Petiana \\ bolsista do Programa de \\ Educação Tutorial (PET) \\ Conexões de Saberes: Diálogos \\ com a Comunidade \\ giovannarrm@gmail.com
}

\author{
Henrique Gabriel Alves Vieira \\ Anacledo Pinheiro \\ Universidade Federal de \\ Rondonópolis (UFR) \\ TSPHen@gmail.com
}

\section{Resumo}

O objetivo do presente trabalho foi realizar revisão sistemática de estudos que descrevessem e avaliassem a aplicação de tecnologias educacionais para o letramento de alunos com Transtornos do Neurodesenvolvimento. Os Transtornos do Neurodesenvolvimento são um grupo de condições que têm início precocemente na vida dos indivíduos e que são caracteridos por déficits no desenvolvimento, levando a prejuizos funcionais em diversas áreas. Foi realizada uma busca de artigos em bases de dados de periódicos Peer Reviewed e foram encontrados 138 trabalhos. Do total encontrado, 22 foram selecionados de acordo com o escopo da pesquisa. Após a avaliação de qualidade, 17 foram utilizados para a revisão. A população mais investigada foi a de alunos com autismo (6), seguido por alunos com dislexia (4) e deficiência intelectual (4). Houve apenas um trabalho para alunos com déficit de atenção e hiperatividade, transtornos de aprendizagem não especificos e um para alunos com gagueira. Em nenhum trabalho participaram individuos com Transtornos do Desenvolvimento Motor. Para alunos com autismo, a maior parte dos trabalhos enfocou no desenvolvimento de habilidades de comunicação. Para alunos disléxicos, ofoco foi em desenvolver consciência fonológica e leitura de palavras. As tecnologias avaliadas consistiram em softwares aplicados por computador e aplicativos acessados via tablet ou celular. Dos estudos avaliados, seis eram experimentais, três eram quasi-experimentais e os demais eram relatos de intervenção. Todos os estudos

Cite as: Rocca, J. Z., Freitas, L. A. B., Campos Junior, R. F, Martins, G. R. R., Pinheiro, H. G. A. V. A., \& Souza, L. C. (2020). Systematic Review of studies assessing the use of educational technology to literacy of students with Neurodevelopmental Disorders in the Brazilian context (Revisão sistemática de estudos de avaliação de tecnologias educacionais para letramento e alfabetização de estudantes com Transtornos do Neurodesenvolvimento no contexto brasileiro). Brazilian Journal of Computers in Education (Revista Brasileira de Informática na Educação - RBIE), 28, 1151-pp. DOI: 10.5753/RBIE.2020.28.0.1151 
experimentais relataram melhora nos repertórios de alunos que participaram da intervenção. Os relatos de experiência também consideraram o uso de tecnologias promissoras, apesar dos desafios para sua implantação no contexto escolar. Conclui-se que o uso de softwares tem contribuido para o processo de letramento de alunos com Transtornos do Neurodesenvolvimento na medida em que (a) facilitam a adaptação e personalização dos materiais; (b) oferecem feedback individualizado e (c) permitem que o aluno progrida em seu próprio ritmo.

Palavras-Chave: Letramento; Tecnologia educacional; Transtornos do neurodesenvolvimento.

\begin{abstract}
The goal of the present work was to carry out a systematic review of studies that described and evaluated the application of educational technologies for the literacy of students with Neurodevelopmental Disorders. Neurodevelopmental disorders are a group of conditions with an early onset and which are characterized by developmental deficits, resulting in impaired personal, social, academic or professional functioning. A search for articles was carried out in databases of Peer Reviewed journals and 138 articles were found. Of these, 23 papers were selected according to the scope of the research and, after quality assessment, 17 were used for the review. The most investigated population was students with autism (6), followed by students with dyslexia (4) and intellectual disability (4). There was only one study for students with attention deficit and hyperactivity disorder, non-specific learning disorders and one for students with stuttering. There was no work with individuals with Motor Development Disorders. Regarding of students with autism, most of the work focused on the development of communication skills. For dyslexia, the focus was generally on phonological awareness and word reading. The evaluated technologies consisted of software applied by computer and applications accessed via tablet or cell phone. Of the total studies evaluated, six were experimental, three were quasi-experimental and the others were reports of intervention. All experimental studies reported an improvement in the repertoires of students who participated in the intervention. The experience reports also considered the use of technologies promising, despite the challenges for their implementation in the school context. It is concluded that the use of software can assist in the process of literacy for students with Neurodevelopmental Disorders insofar as (a) it facilitates the adaptation and customization of materials; (b) offers individualized feedback and (c) allows the student to progress at their own pace.
\end{abstract}

Keywords: Literacy; Educational technology; Neurodevelopmental Disorders.

\title{
1 Introdução
}

Os Transtornos do Neurodesenvolvimento, conforme o DSM V (APA, 2013) são um conjunto de condições com início precoce e que se caracterizam por déficits no desenvolvimento, acarretando prejuízos no funcionamento pessoal, social, acadêmico ou profissional. Esses déficits podem ser muito variados, desde limitações mais brandas e específicas na aprendizagem até prejuízos amplos em áreas como habilidades sociais e inteligência. O nível de sobreposição destas características entre os transtornos do neurodesenvolvimento é alto, isso justifica seu agrupamento sob uma mesma categoria mais ampla (Thapar, Cooper \& Rutter, 2017).

Os transtornos incluídos na categoria de Transtornos do Neurodesenvolvimento pelo DSMV (APA, 2013) são1: o Transtorno do Desenvolvimento Intelectual (DI - ou Deficiência Intelectual), os Transtorno da Comunicação (subdividido em várias subcategorias), o Transtorno do Espectro Autista (TEA), Transtorno de Déficit de Atenção/Hiperatividade (TDAH), o Transtorno Específico da Aprendizagem, os Transtornos Motores (com várias subcategorias) e Outros Transtornos do Neurodesenvolvimento. Thapar, Cooper e Rutter (2017) afirmam que a avaliação e o tratamento de crianças com estes transtornos exigem diversos especialistas, nas áreas da saúde e da educação. Portanto, o tratamento é multidisciplinar e de longo prazo.

A frequência com que os déficits característicos dos transtornos podem persistir ou apresentar remissão na vida adulta podem variar. Por exemplo, estima-se que os sintomas típicos do TDAH persistam em 15\% dos indivíduos na idade adulta (Faraone, Biederman, \& Mick, 2006). Em outro estudo, Whitehouse et al. (2009) verificaram que déficits nas habilidades de linguagem, de leitura e de escrita tendem a persistir na idade adulta em indivíduos diagnosticados com Transtornos da

\footnotetext{
${ }^{1}$ Uma breve descrição de cada categoria será apresentada na seção 1.3 Definições utilizadas para revisão
} 
Comunicação e TEA na infância. Sugerindo, portanto, a necessidade de implementar estratégias educativas de longo prazo que visem promover e desenvolver essas habilidades.

A implementação destas estratégias educativas, geralmente ocorrem no ambiente escolar, embora não estejam restritas a ele. No Brasil, a lei no 13.146/2015, popularmente conhecida como "Lei Brasileira da Inclusão", foi elaborada com o objetivo de "assegurar e promover, em condições de igualdade, o exercício dos direitos e das liberdades fundamentais por pessoa com deficiência, visando à sua inclusão social e cidadania" (Brasil, 2015). Esta lei, além de ampliar o a definição de pessoa com deficiência - o que inclui pessoas com Transtornos do Neurodesenvolvimento - destaca o papel central que as tecnologias têm na inclusão social desta população. O termo tecnologia é utilizado em diversos artigos, geralmente fazendo referência ao uso de tecnologia assistiva para a garantia de acesso a direitos fundamentais, mas também, para afirmar que devem ser estimuladas a pesquisa, o desenvolvimento, a inovação e a difusão de tecnologias que ampliem o acesso de pessoas com deficiência às tecnologias da informação e comunicação, além de funcionarem como instrumentos para superar limitações funcionais.

Apesar da promulgação de uma lei que propõe o incentivo ao desenvolvimento tecnológico em benefício das pessoas com deficiência, os desafios da inclusão de estudantes com Transtornos do Neurodesenvolvimento vêm sendo endereçados por vários autores (e.g., Almerini, 2014; Benini \& Castanha, 2016). Ainda que a tecnologia apareça como um recurso necessário e promissor para viabilizar ou facilitar que a escola desempenhe seu papel na inclusão escolar e social (Bishop, 2003; Wehmeyer, Smith, Palmer \& Davies, 2004), pouco se sabe sobre o uso de recursos tecnológicos e como eles vêm sendo utilizados no contexto brasileiro.

Um dos usos possíveis da tecnologia na educação é como suporte à alfabetização e ao letramento e, nas palavras de Bergtson e Pino (2018, p. 28), "letramento é uma forma de inclusão". As definições de alfabetização e de letramento são complexas e sofreram mudanças ao longo do tempo, variando, inclusive, entre países (Soares, 2004). Para Soares (2004), apesar de distintos, os dois processos estão intimamente relacionados e são indissociáveis. A alfabetização está mais ligada ao aprendizado do sistema convencional da escrita e o letramento, por sua vez, se refere a desenvolver habilidades de uso do sistema por meio do envolvimento em atividades como ler, escrever e outras práticas sociais que se relacionam à língua escrita.

Segundo Galvani e Mendes (2018), a alfabetização e o letramento de estudantes com deficiências ocorrem de modo sistêmico, ordenado e progressivo, com início em atividades que podem incluir o reconhecimento de sons e letras, memorização e avançar para a escrita e a leitura de palavras e pequenos textos. No presente trabalho, o papel da tecnologia na avaliação e no ensino de estudantes com Transtornos do Neurodesenvolvimento foi endereçada em relação a uma dimensão específica da escolarização: o letramento. O processo de aprendizagem da leitura e da escrita tem papel central para a aprendizagem escolar uma vez que a maior parte dos conteúdos e atividades é apresentado em linguagem escrita. A criação de recursos específicos pode viabilizar a aprendizagem para indivíduos com Transtornos do Neurodesenvolvimento.

Com o objetivo de investigar as tecnologias que vêm sendo utilizadas para a alfabetização de pessoas com TEA, da Silva et al. (2020) realizaram uma revisão sistemática da literatura entre os anos de 2014 e 2019. As autoras realizaram suas buscas nas bases eletrônicas Scielo e Capes e, após a aplicação dos critérios de inclusão e exclusão, selecionaram para análise sete estudos. A maioria dos trabalhos analisados utilizou abordagem qualitativa e a análise dos resultados foi apresentada de forma descritiva. A análise dos meios de aplicação das tecnologias revelou que os softwares e aplicativos vêm sendo utilizados em iPads, tablets, smartphones, laptops e computadores desktop e que os resultados em geral são positivos.

Em outro estudo, também circunscrito ao público com TEA, Ferreira et al. (2018) revisaram sistematicamente publicações brasileiras que trataram do tema "Autismo, Educação e 
Tecnologia". Os autores efetuaram buscas em diversos repositórios de artigos nacionais com o período de publicação entre os anos de 2002 e 2017. Foram selecionados e analisados ao todo 33 trabalhos. Os autores verificaram que os trabalhos enfocaram em duas áreas: comunicação e habilidades sociais. $\mathrm{Na}$ área da comunicação, houve predominância de trabalhos sobre alfabetização e letramento, mas também direcionados a habilidades como raciocínio e percepção visual. A eficácia destas tecnologias para o desenvolvimento de habilidades, no entanto, não foi abordada no estudo, pois este tipo de análise não foi mencionado nas 33 publicações contempladas.

Com uma perspectiva mais ampla e em busca de estudos de alta qualidade metodológica, Khan et al. (2019) realizaram uma revisão sobre a efetividade de intervenções baseadas em WEB para crianças e jovens com Transtornos do Neurodesenvolvimento. Os autores, incluíram somente estudos que realizaram experimentos controlados com amostra randomizada, considerado padrão ouro para práticas baseadas em evidências (Moher, Liberati, Tetzlaff, \& Altman, 2009). Khan et al. encontraram dez estudos que atendiam a esses critérios, sendo cinco dedicados a pessoas com TEA e outros cinco trabalhando com pessoas com TDAH. Seis das dez intervenções apresentaram resultados positivos quando comparados os grupos experimental e controle. Os quatro casos em que não houve efeito, consistiam em intervenções utilizando aplicativo em dispositivos móveis. Para Khan et al. há viabilidade no uso de tecnologias transmitidas via WEB para essas populações, mas é fundamental a realização de mais pesquisas.

Igualmente concentrada no público com Transtornos do Neurodesenvolvimento, a revisão sistemática de Valentine et al. (2020), investigou o uso de tecnologias na avaliação, diagnóstico e tratamento de pessoas em contexto clínico, excluindo-se os estudos em contextos educacionais ou que visavam inserção no mercado de trabalho. Dos 47 estudos analisados, a maior parte incluiu pessoas com TEA e TDAH, e teve como objetivo principal o monitoramento o tratamento desses indivíduos.

No contexto brasileiro, as revisões de da Silva et al. (2020) e Ferreira et al. (2018), mencionadas anteriormente, oferecem um breve panorama do que vem sendo produzido no que se refere ao uso de tecnologias educacionais para indivíduos com TEA, em diferentes contextos e com abrangências distintas. Em um contexto internacional e com um público mais diverso, estudos como o de Khan et al. (2019) e o de Valentine et al. (2020) têm indicado o emprego de tecnologias com pessoas com Transtornos do Neurodesenvolvimento tem sido objeto de investigação e podem ser eficazes para diferentes usos, a depender de fatores como o meio de aplicação. Nota-se, portanto, a existência de uma lacuna no que se refere a trabalhos que tenham abordado o uso de tecnologias educacionais com enfoque na alfabetização e no letramento para um público mais amplo, com deficiências que abrangem um espectro mais diverso - como é o caso das pessoas com Transtornos do Neurodesenvolvimento - no contexto de escolas brasileiras. Assim a condução do presente trabalho visou levantar dados acerca da literatura recente que possam contribuir para a redução desta lacuna.

\section{Objetivo}

Realizar uma revisão sistemática de trabalhos que descrevam e avaliem a aplicação de tecnologias educacionais para o letramento, alfabetização de pessoas com Transtornos do Neurodesenvolvimento e/ou desenvolvimento de habilidades relacionadas à leitura e escrita nestes indivíduos no contexto brasileiro. 


\section{Questões de pesquisa}

A fim de delimitar claramente os produtos esperados da revisão, as seguintes perguntas nortearam esta pesquisa: quais os resultados encontrados em estudos brasileiros na aplicação de tecnologias educacionais para o letramento e alfabetização de alunos com Transtorno do Neurodesenvolvimento? Dentre os Transtornos do Neurodesenvolvimento, quais foram as populações mais estudadas? Que tipo de tecnologia educacional foi utilizada nos estudos investigados? Qual o meio de aplicação de softwares ou aplicativos? Qual o método de avaliação dos resultados das intervenções usando tecnologias? Quais seriam os custos para aplicação desses recursos em contexto educacionais?

\section{Definições utilizadas para a revisão}

Para a condução da presente revisão, buscou-se a adoção de definições claras para alguns termos como forma de subsidiar a seleção e análise dos trabalhos encontrados. Estas definições são apresentadas a seguir.

\subsection{Letramento}

O Relatório do National Reading Panel (NICHD, 2000) considerou as seguintes habilidades como componentes da aprendizagem da leitura: decodificação, consciência fonológica, fluência, compreensão de texto e vocabulário. Em uma perspectiva mais abrangente, para o grupo de trabalho que avaliou os estudos científicos da área de letramento em pré-escolares (National Early Literacy Panel, 2008), as habilidades foco incluíam também: conhecimento sobre o alfabeto; nomeação automática rápida de letras; nomeação automática rápida de figuras de objetos; escrita do próprio nome; memória fonológica e conhecimentos a respeito da linguagem escrita; linguagem oral e processamento visual. Soares (2004), como mencionado anteriormente, também distingue os processos de alfabetização e letramento, além de destacar que os dois estão intimamente relacionados e são essenciais para o aprendizado e o uso social da leitura e da escrita.

Deste modo, a presente revisão focalizou uma população com grande diversidade de déficits e potenciais, de modo que seu percurso de aprendizagem, bem como os objetivos do processo de ensino, podem variar amplamente. Assim, além do conceito de alfabetização, conforme definido pelo National Reading Panel (NICHD, 2000), no presente estudo optou-se por adotar uma definição de letramento mais abrangente, incluindo o desenvolvimento de habilidades de comunicação, perceptuais e motoras que estão relacionadas ao uso social da leitura e escrita (Soares, 2004).

\subsection{Tecnologia educacional}

Tecnologia educacional é definida como o estudo e prática ética de facilitar a aprendizagem ou melhorar a performance pela criação, uso ou gerenciamento de processos e recursos tecnológicos (Glaeser, 2015). Desse modo, o termo reúne as atividades e o domínio de conhecimento que se situam na área de intersecção entre tecnologia e educação.

\subsection{Transtornos do Neurodesenvolvimento}

A deficiência intelectual (Transtorno do Desenvolvimento Intelectual) caracteriza-se por déficits em capacidades mentais genéricas, como raciocínio, solução de problemas, planejamento, pensamento abstrato, juízo, aprendizagem acadêmica e aprendizagem pela experiência (APA, 2013). Os déficits resultam em prejuízos no funcionamento adaptativo, de modo que o indivíduo não consegue atingir padrões de independência pessoal e responsabilidade social em um ou mais 
aspectos da vida diária, incluindo comunicação, participação social, funcionamento acadêmico ou profissional e independência pessoal em casa ou na comunidade.

Os Transtornos da Comunicação incluem o transtorno da linguagem, o transtorno da fala, o transtorno da comunicação social (pragmática) e o transtorno da fluência com início na infância (gagueira). Os três primeiros caracterizam-se por déficits no desenvolvimento e no uso da linguagem, da fala e da comunicação social, respectivamente. O transtorno da fluência com início na infância é caracterizado por perturbações da fluência normal e da produção motora da fala, incluindo sons ou sílabas repetidas, prolongamento de sons de consoantes ou vogais, interrupção de palavras, bloqueio ou palavras pronunciadas com tensão física excessiva (APA, 2013).

O Transtorno do Espectro Autista (TEA) caracteriza-se por déficits persistentes na comunicação social e na interação social em múltiplos contextos, incluindo déficits na reciprocidade social, em comportamentos não verbais de comunicação usados para interação social e em habilidades para desenvolver, manter e compreender relacionamentos (APA, 2013). Além de dificuldades na comunicação social, o diagnóstico do TEA requer a presença de padrões restritos e repetitivos de comportamento, interesses ou atividades.

O Transtorno de Déficit de Atenção e Hiperatividade (TDAH) é um Transtorno do Neurodesenvolvimento definido por níveis prejudiciais de desatenção, desorganização e/ou hiperatividade-impulsividade. Desatenção e desorganização envolvem incapacidade de permanecer em uma tarefa, aparência de não ouvir e perda de materiais em níveis inconsistentes com a idade ou o nível de desenvolvimento. Hiperatividade-impulsividade implicam atividade excessiva, inquietação, incapacidade de permanecer sentado, intromissão em atividades de outros e incapacidade de aguardar - sintomas que são excessivos para a idade ou o nível de desenvolvimento (APA, 2013).

Um Transtorno Específico da Aprendizagem, como o nome implica, é diagnosticado diante de déficits específicos na capacidade individual para perceber ou processar informações com eficiência e precisão. Este Transtorno do Neurodesenvolvimento manifesta-se, inicialmente, durante os anos de escolaridade formal, caracterizando-se por dificuldades persistentes e prejudiciais nas habilidades básicas acadêmicas de leitura, escrita e/ou matemática, popularmente conhecidos por dislexia, disgrafia e discalculia, respectivamente. O desempenho individual nas habilidades acadêmicas afetadas está bastante abaixo da média para a idade, ou níveis de desempenho aceitáveis são atingidos somente com esforço extraordinário. $O$ Transtorno Específico da Aprendizagem pode ocorrer em pessoas identificadas como apresentando altas habilidades intelectuais e manifestar-se apenas quando as demandas de aprendizagem ou procedimentos de avaliação (e.g., testes cronometrados) impõem barreiras que não podem ser vencidas pela inteligência inata ou por estratégias compensatórias (APA, 2013).

Ainda dentro dos Transtornos do Neurodesenvolvimento, estão as classificações de Transtornos Motores e de Outros Transtornos do Neurodesenvolvimento. Entretanto, como não foram encontrados trabalhos que incluíssem participantes com estes transtornos, suas características não serão detalhadas.

\section{Método}

Para realizar a inclusão dos artigos na pesquisa, seguiu-se o fluxograma apresentado na Figura 1. Iniciando-se pela identificação dos artigos, passando para a seleção e finalmente a avaliação. A seleção baseou-se em três critérios: escopo, inclusão e exclusão. Os detalhes da avaliação serão apresentados mais adiante. 


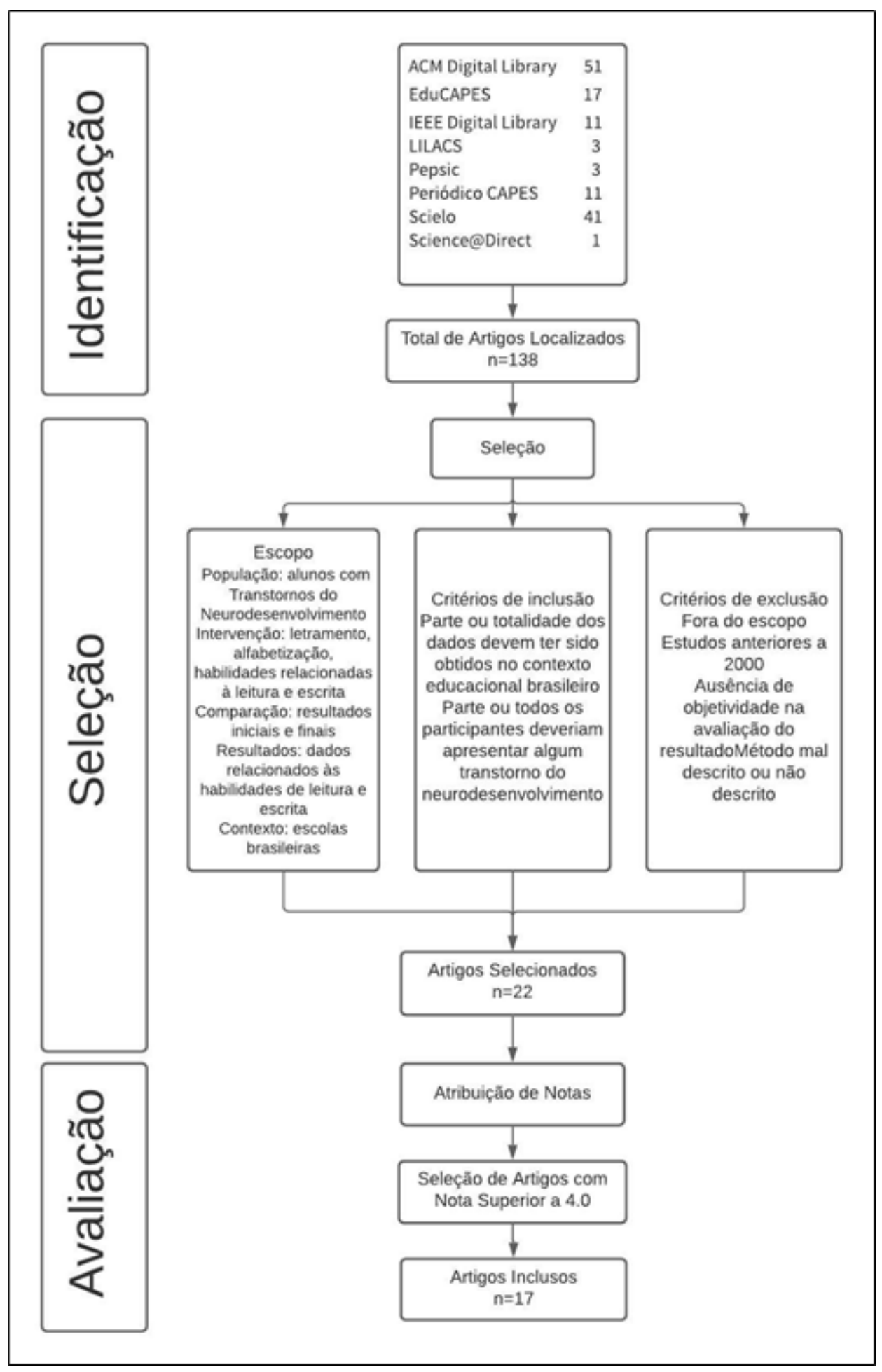

Figura 1: Fluxograma de inclusão de trabalhos.

Inicialmente, foi realizada busca de trabalhos em bases de dados de periódicos Peer Reviewed. O conjunto de bases de dados que integrou a pesquisa incluiu:

ACM Digital Library (http://portal.acm.org)

EduCAPES (https://educapes.capes.gov.br)

El Compendex (https://www.elsevier.com/solutions/engineering-village/content/compendex)

IEEE Digital Library (http://ieeexplore.ieee.org) 
ISI Web of Science (http://www.isiknowledge.com)

\section{LILACS (https://lilacs.bvsalud.org)}

Pepsic (http://pepsic.bvsalud.org/)

Periódico CAPES (https://www.periodicos.capes.gov.br)

\section{Scielo (https://scielo.org/)}

\section{Science@Direct (http://www.sciencedirect.com)}

\section{Scopus (http://www.scopus.com)}

\section{Springer Link (http://link.springer.com)}

O intervalo de tempo em que as buscas foram realizadas foi de 2 meses consecutivos. As palavras-chave utilizadas para a pesquisa estão contidas na Tabela 1, assim como a string de busca utilizada.

Tabela 1: Palavras utilizadas na busca de artigos.

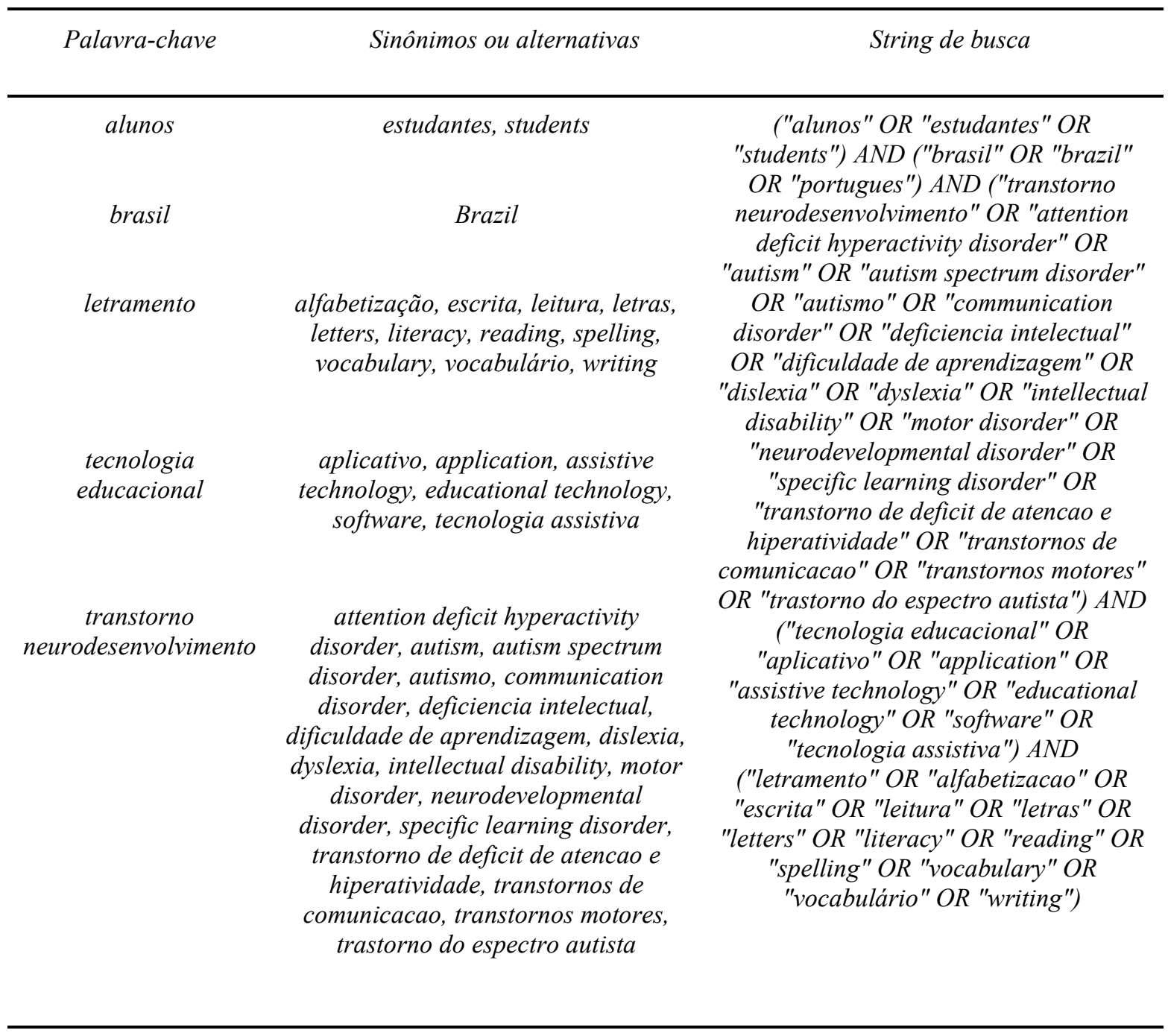


A string foi utilizada em 6 bases de dados ${ }^{2}$, e nas bases que não suportavam o uso da string ${ }^{3}$, as palavras-chave foram combinadas sistematicamente para que fosse viável a realização das buscas (e.g., "autism" and "educational" and "technology"). A busca retornou 138 trabalhos, os quais foram analisados por meio da leitura do título e do resumo, considerando o escopo, os critérios de inclusão e exclusão. Em seguida, os trabalhos foram selecionados e importados para a Plataforma Evidências - Módulo Sumarize ${ }^{4}$ para que fosse possível organizá-los e, posteriormente, extrair as informações relevantes para a preparação deste artigo.

Em função do escopo da pesquisa, o contexto escolhido refere-se às escolas brasileiras, e os demais itens considerados na seleção dos trabalhos foram apresentados na Tabela 2. Referente aos critérios de inclusão, o uso apenas de trabalhos brasileiros, decorre-se do fato de que os processos de letramento são específicos para cada língua, de modo que tecnologias de ensino de letramento para línguas estrangeiras não necessariamente atenderiam à população brasileira. Além disso, devido à emergência da utilização de novas tecnologias, que considerem a complexidade do desenvolvimento de habilidades envolvidas no letramento e na alfabetização de crianças com desenvolvimento atípico, a presença de crianças com Transtorno do Neurodesenvolvimento como participantes dos estudos foi considerada crucial para avaliação da possível aplicabilidade e validade dessas tecnologias.

No que diz respeito aos critérios de exclusão, a eliminação de trabalhos anteriores ao ano 2000 justifica-se pelo contínuo avanço tecnológico que poderia tornar os estudos publicados anteriormente a essa data defasados, uma vez que possivelmente incluiriam tecnologias descontinuadas ou para as quais já não há suporte disponível.

Tabela 2: Itens avaliados para seleção dos artigos.

\begin{tabular}{cc}
\hline Seleção & Itens \\
\hline Escopo & $\begin{array}{c}\text { População: alunos com Transtornos do Neurodesenvolvimento } \\
\text { Intervenção: letramento, alfabetização, habilidades relacionadas à leitura e escrita } \\
\text { Comparação: resultados iniciais e finais } \\
\text { Resultados: dados relacionados às habilidades de leitura e escrita } \\
\text { Contexto: escolas brasileiras }\end{array}$ \\
Critérios de inclusão & $\begin{array}{c}\text { Parte ou totalidade dos dados devem ter sido obtidos no contexto educacional } \\
\text { brasileiro }\end{array}$ \\
Parte ou todos os participantes deveriam apresentar algum transtorno do \\
neurodesenvolvimento \\
Fritérios de exclusão \\
Fuserncia de objetividade na avaliação do resultado \\
Método mal descrito ou não descrito
\end{tabular}

2 ACM, EduCAPES, IEEE Digital Library, LILACS, Pepsic, Periódico CAPES.

${ }^{3}$ Ei Compendex, ISI Web of Science, Scielo, Science@Direct, Scopus, Springer Link.

4 A Plataforma Evidências foi desenvolvida pelo Núcleo de Excelência em Tecnologias Sociais, da Universidade Federal de Alagoas, especializada em pesquisa, desenvolvimento e inovação de tecnologias educacionais, e contou com a colaboração de pesquisadores da Universidade de São Paulo. O objetivo da Plataforma é possibilitar a realização de revisões sistemáticas, auxiliando os pesquisadores a planejar, conduzir, exportar e construir metanálises da sua revisão. Disponível em: https://sumarize.evidencias.nees.com.br/. 
Dentre os 138 trabalhos, foram selecionados 22. Estes trabalhos foram analisados por duas pessoas separadamente na Plataforma Evidências - Módulo Sumarize e, em caso de discordância, um terceiro analista avaliou o trabalho para decidir pela sua inclusão ou exclusão.

Os trabalhos também foram analisados em relação à presença ou ausência dos elementos apresentados na Tabela 3. Os critérios buscaram hierarquizar os estudos de acordo com os seus níveis de evidências e qualidade. Assim como a hierarquia de Camanho (2009), trabalhos randomizados com técnica adequada, ou meta-análises possuem maior nível de evidência tendo recebido notas maiores, os estudos coorte, caso-controle, série de casos, relato de casos receberam notas menores, mas os que atingiram critérios de qualidade, também foram incluídos na análise. Assim como em Galvão e Pereira (2015), vale ressaltar a importância em considerar os níveis de evidência, pois quanto mais próximo da base hierárquica (opinião de especialista, descrição de casos), maior a chance de existirem vieses ou do trabalho exprimir apenas uma individualidade.

Tabela 3: Critérios para avaliação de artigos

\begin{tabular}{|c|c|c|}
\hline Questão & Item avaliado & Pontos \\
\hline $\begin{array}{l}\text { A tecnologia educacional está descrita de modo } \\
\text { completa ou são apresentadas referências onde essa } \\
\text { descrição pode ser encontrada? }\end{array}$ & Presença de descrição clara ou referência. & 2,5 \\
\hline $\begin{array}{c}\text { A descrição dos participantes com transtorno de } \\
\text { neurodesenvolvimento apresenta suas habilidades } \\
\text { básicas relacionadas à leitura e escrita? }\end{array}$ & $\begin{array}{l}\text { Presença de descrição completa das } \\
\text { características dos participantes. }\end{array}$ & 2,5 \\
\hline $\begin{array}{c}\text { A descrição dos resultados apresenta dados } \\
\text { quantitativos de desempenhos de leitura, escrita ou } \\
\text { habilidades relacionadas? }\end{array}$ & Presença de resultados quantitativos. & 1 \\
\hline É um estudo de caso? & $\begin{array}{l}\text { Descrição detalhada, usando múltiplas } \\
\text { fontes de coleta de dados, de um caso. }\end{array}$ & 0,2 \\
\hline É um estudo com poucos participantes? & $\mathrm{N}$ igual ou inferior a 6. & 0,3 \\
\hline É um survey? & $\begin{array}{l}\text { Há coleta de dados junto ao grande } \\
\text { número de pessoas. }\end{array}$ & 0,3 \\
\hline É um estudo experimental? & Há manipulação de variáveis. & 0,5 \\
\hline É um estudo clínico randomizado? & $\begin{array}{c}\text { Se houver pelo menos dois grupos que } \\
\text { foram selecionados aleatoriamente a partir } \\
\text { de um conjunto homogêneo de } \\
\text { participantes. }\end{array}$ & 1,0 \\
\hline $\begin{array}{l}\text { O estudo usa recursos como: cego, duplo cego, } \\
\text { delineamentos de sujeito como próprio controle, } \\
\text { etc. }\end{array}$ & Presença dos elementos citados. & 1,0 \\
\hline $\begin{array}{l}\text { A seção de resultados apresenta descrição detalhada } \\
\text { de dados, seja quantitativa ou qualitativa? }\end{array}$ & Presença de descrição detalhada. & 1,7 \\
\hline
\end{tabular}

Os 22 trabalhos selecionados na etapa anterior foram lidos integralmente e avaliados seguindo os critérios descritos na Tabela 3. As pontuações atribuídas a cada critério eram somadas e apenas os trabalhos com pontuação superior a quatro foram incluídos na revisão. Ao final desta etapa, 17 
trabalhos obtiveram pontuação superior a quatro, os demais foram excluídos. Na etapa seguinte, foi realizada a extração de dados dos trabalhos incluídos.

Para proceder a extração dos dados, foi criado um formulário com os campos necessários na Plataforma Evidências. A inserção dos dados no formulário ocorreu de forma semi-automatizada, tendo sido inicialmente recuperados dos dados inseridos no sistema na etapa anterior, mas posteriormente revisados e complementados pelos avaliadores. $\mathrm{O}$ conjunto de dados extraídos nesta etapa subsidiou a elaboração dos resultados apresentados a seguir.

\section{Resultados}

\subsection{População investigada}

A população que foi investigada no maior número de estudos foi de alunos com TEA, com seis estudos (35\%). Em dois trabalhos, participaram alunos com TEA e alunos DI indistintamente (12\%). Em dois outros estudos participaram apenas alunos com DI (12\%). A dislexia, único Transtorno da Aprendizagem presente entre os trabalhos analisados, teve quatro estudos dedicados a essa população (23\%). Com populações com TDAH, dificuldades de aprendizagem sem outra especificação e Transtorno da Comunicação - gagueira, foi analisado um artigo (6\%) cada.

A distribuição de participantes com os diferentes diagnósticos entre os estudos, entretanto, é diferente. Observa-se na Tabela 4, que o maior número de participantes nos estudos teve diagnóstico de Dislexia (37,4\%), seguidos pelo TDAH (34,5\%) e TEA (27,8\%). As populações menos investigadas tinham dificuldades de aprendizagem sem outra especificação $(0,4 \%)$, gagueira $(5,7 \%)$ e DI $(12,1 \%)$.

Em um dos trabalhos (Guerra \& Furtado, 2013) os participantes tinham ao mesmo tempo dois diagnósticos, de TEA e de TDAH. Benitez e Domeniconi (2018) foi o único estudo que teve participantes de duas populações diferentes (DI e TEA), sem que os diagnósticos tenham ocorrido em comorbidade.

Tabela 4: Distribuição de participantes dos estudos por diagnóstico

\begin{tabular}{|c|c|c|c|c|c|c|}
\hline \multirow[t]{2}{*}{ Trabalhos } & \multicolumn{6}{|c|}{ Diagnósticos } \\
\hline & TEA & DI & Dislexia & $\begin{array}{c}\text { Transtorno } \\
\text { de } \\
\text { aprendizage } \\
\text { m não } \\
\text { específico }\end{array}$ & TDAH & $\begin{array}{c}\text { Transtorno } \\
\text { s de } \\
\text { Comunica } \\
\text { ção }\end{array}$ \\
\hline Germano e Capellini (2008) & - & - & 10 & - & - & - \\
\hline $\begin{array}{l}\text { Oliveira, Lukasova e Macedo } \\
\text { (2010) }\end{array}$ & - & - & 10 & - & - & - \\
\hline Guerra e Furtado (2013) & $50 *$ & - & - & - & $50 *$ & - \\
\hline Ribeiro et al. (2013) & 4 & - & - & - & - & - \\
\hline
\end{tabular}


Nunes e Walter (2014)

Verdu e de Oliveira (2014)

Oliveira et al. (2015)

Buzzeti et al. (2016)

Martins et al. (2016)

de Santana, Guimarães e Mattos (2016)

Bittencourt e Fumes (2017)

Magaton e Bim (2017)

Benitez e Domeniconi (2018)

Pisacco et al. (2018)

Rosa, Silva e Aymone (2018)

Zavaleta et al. (2018)

Menotti, Domeniconi e Benitez (2019)
14

11

4

6

5

9

11
16

2

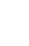


Tabela 5: Distribuição de participantes dos estudos por faixa etária.

\begin{tabular}{|c|c|c|c|c|c|}
\hline \multirow[b]{2}{*}{ Trabalhos } & \multicolumn{5}{|c|}{ Idade } \\
\hline & 5-7 & 8-10 & 11-13 & $\geq 14$ & Outro \\
\hline Germano e Capellini (2008) & - & $10^{*}$ & - & - & - \\
\hline Oliveira, Lukasova e Macedo (2010) & - & - & $10^{*}$ & - & - \\
\hline Guerra e Furtado (2013) & - & - & - & - & $\begin{array}{l}50(4 \text { a } 18 \\
\text { anos })\end{array}$ \\
\hline Ribeiro et al. (2013) & 2 & - & 2 & - & - \\
\hline Nunes e Walter (2014) & - & - & - & - & $\begin{array}{c}\text { Não } \\
\text { especificado }\end{array}$ \\
\hline Verdu e de Oliveira (2014) & - & - & 1 & - & - \\
\hline Oliveira et al. (2015) & - & - & $14^{*}$ & - & - \\
\hline Buzzeti et al. (2016) & - & - & $16^{*}$ & - & - \\
\hline Martins et al. (2016) & - & $2 *$ & - & - & - \\
\hline $\begin{array}{c}\text { de Santana, Guimarães e Mattos } \\
\text { (2016) }\end{array}$ & - & - & - & 11 & - \\
\hline Bittencourt e Fumes (2017) & - & - & - & 4 & - \\
\hline Magaton e Bim (2017) & 4 & 2 & - & - & - \\
\hline Benitez e Domeniconi (2018) & - & 12 & 2 & - & - \\
\hline Pisacco et al. (2018) & - & - & $47^{*}$ & - & - \\
\hline Rosa, Silva e Aymone (2018) & - & - & - & - & 4 (4 a 10 anos) \\
\hline Zavaleta et al. (2018) & - & - & - & - & $\begin{array}{c}\text { Não } \\
\text { especificado }\end{array}$ \\
\hline $\begin{array}{l}\text { Menotti, Domeniconi e Benitez } \\
\text { (2019) }\end{array}$ & - & - & 3 & - & - \\
\hline Total & 6 & 26 & 95 & 15 & - \\
\hline
\end{tabular}


Outros trabalhos, como o de Germano e Capellini (2008) e Oliveira et al. (2015), descreveram apenas a média de idade dos participantes. Considerados somente os trabalhos em que foi possível identificar a idade exata ou uma faixa etária média dos participantes, a faixa entre 11 e 13 anos foi a que teve mais participantes (95). A faixa que teve menos participantes foi a de 5 a 7 anos de idade. A seguir, será apresentada uma caracterização descritiva dos trabalhos organizados conforme o público investigado.

\subsubsection{Alunos com Transtornos do Espectro Autista (TEA)}

Para o público com TEA, a maioria das intervenções focalizou o desenvolvimento de aplicativos voltados à comunicação, utilizando recursos visuais como figuras e animações (Ribeiro, Braz, Raposo \& Silva, 2013; Guerra \& Furtado, 2013; Bittencourt \& Fumes, 2017; Magaton \& Bim, 2017; Rosa, Silva \& Aymone, 2018). Menos frequentemente, trabalhou-se com leitura e escrita de palavras (Menotti, Domeniconi \& Benitez, 2019; Magaton \& Bim, 2017). Esses recursos foram utilizados exclusivamente com alunos com habilidades verbais funcionais (Bittencourt et al., 2017; Domeniconi et al, 2019) e com grupos incluindo alunos verbais e não verbais (Ribeiro et al., 2013; Guerra \& Furtado, 2013; Magaton \& Bim, 2017; Rosa et al., 2018).

Com exceção do trabalho de Menotti et al. (2019), os demais estudos não mensuraram respostas específicas dos participantes de modo a comparar seu desempenho antes, durante e depois da intervenção. Em geral, os artigos descreveram os resultados das experiências de ensino e incluíam informações sobre as opiniões de pais e terapeutas (Ribeiro et al., 2013; Guerra \& Furtado, 2013; Bittencourt \& Fumes, 2017; Magaton \& Bim, 2017; Rosa et al., 2018). Além disso, somente Menotti et al. (2019) utilizaram procedimentos de controle experimental. As autoras trabalharam com o delineamento de linha de base múltipla entre palavras (Cooper, Heron, \& Heward, 2007). Este procedimento permite averiguar comparativamente os efeitos da intervenção (variável independente) sobre o desempenho do participante (variável dependente).

Em relação aos resultados, todos os artigos consideraram que as tecnologias avaliadas apresentavam contribuições importantes para o público-alvo. Entretanto, alguns autores especificaram dificuldades relacionadas à atenção nas atividades realizadas (Ribeiro et al., 2013; Guerra \& Furtado, 2013; Magaton \& Bim, 2017; Rosa et al., 2018). Também relataram a demanda por personalização de aspectos visuais ou auditivos, considerando que esse público pode ter hipo ou hipersensibilidade (Guerra \& Furtado, 2013; Magaton \& Bim, 2017; Rosa et al., 2018). Entretanto, é frequente o relato de que alunos com autismo teriam facilidade ou predileção pelo uso dos recursos tecnológicos (Ribeiro et al., 2013; Guerra \& Furtado, 2013; Magaton \& Bim, 2017; Rosa et al., 2018).

\subsubsection{Alunos com Deficiência Intelectual (DI)}

Entre os estudos realizados com alunos com Deficiência Intelectual, dois são bastante específicos para habilidades de letramento, utilizando softwares específicos para essa função (Oliveira, Saddy, Mograbi \& Coelho, 2015; Benitez \& Domeniconi, 2018). Os outros dois estudos fizeram uso de softwares genéricos disponíveis no mercado para trabalhar outras competências. Um estudo trabalhou habilidades de comunicação utilizando pranchas com figuras ou fotos (Nunes \& Walter, 2014) e o último visou a profissionalização de adolescentes e adultos, e trabalhou com a cópia realizada no computador.

Os trabalhos de Oliveira et al. (2015) e Benitez e Domeniconi (2018) utilizaram comparação entre grupo experimental e controle para avaliar a eficácia dos programas de ensino, respectivamente o software Alfabetização Fônica e uma versão adaptada do Programa Aprendendo a Ler e Escrever em Pequenos Passos, parte do currículo descrito em de Souza, de Rose e Domeniconi (2009). No primeiro caso, foram verificadas diferenças significativas para as habilidades de leitura de palavras e pseudopalavras, identificação de sentenças que representam 
uma cena e compreensão de sentenças, verificada através da resposta a questões a respeito do conteúdo destas. No trabalho de Benitez e Domeniconi (2018), todos os estudantes do grupo experimental apresentaram melhores desempenhos na leitura e na escrita na avaliação final, entretanto, a intensidade do aumento variou entre eles. Os estudantes do grupo controle não apresentaram diferenças entre os resultados iniciais e finais, com exceção de um aluno.

Os outros dois estudos realizaram análise qualitativa de seus resultados, descrevendo, de forma mais ampla, como o trabalho foi desenvolvido e percebido pelos estudiosos e pelas equipes escolares. Nunes e Walter (2014) relataram resultados de um programa contínuo de treinamento e apoio à equipe escolar para a utilização de comunicação alternativa. Os autores avaliaram que esse trabalho melhorou o potencial de comunicação do público-alvo, ainda que, segundo sua observação, as manifestações de comunicação espontânea ainda fossem restritas. De Santana et al. (2016) discutiram a importância de utilizar os equipamentos e softwares que já estão disponíveis no ambiente escolar na construção de programas que viabilizem a profissionalização dos indivíduos com deficiência intelectual. E, neste processo, o letramento teria papel central. Na avaliação dos autores, apesar de grande variação individual, os alunos demonstraram progresso e engajamento nas atividades. Apesar de dois estudos incluírem alunos com TEA (Nunes \& Walter, 2014 e Benitez \& Domeniconi, 2018), o critério de inclusão dos participantes se referiu à sua deficiência intelectual, por isso estes foram reunidos aqui. Conforme discutido anteriormente, a incidência de comorbidades dos Transtornos do Neurodesenvolvimento é alta (King, 2016), portanto, essa sobreposição era previsível.

\subsubsection{Alunos com Transtorno de Aprendizagem Específica - Dislexia}

Quatro trabalhos foram desenvolvidos avaliando tecnologias voltadas para o letramento de alunos com dislexia. Em dois deles, os aplicativos apresentavam palavras (Martins, Sampaio, Lima \& Guimarães, 2016) ou textos de baixa complexidade (Zavaleta et al., 2018) e o aluno deveria ler em voz alta. Sua resposta era, então, gravada e avaliada em relação a correção e tempo de resposta (palavras por minuto, no caso dos textos). Esses resultados foram utilizados para o monitoramento e como ferramenta auxiliar para o diagnóstico da dislexia. Estes estudos trabalharam com pessoas com desenvolvimento típico, casos suspeitos de dislexia e casos diagnosticados. Apesar de não haver uma análise quantitativa mais detalhada, os autores avaliaram essas tecnologias como promissoras para auxiliar na tomada de decisão por especialistas da área.

Os outros dois trabalhos tiveram o objetivo de avaliar a eficácia de softwares visando o ensino remediativo de habilidades relacionadas à leitura e à escrita. Germando e Capellini (2008) usaram o software Play on - Jeu d'entraînement à la lecture, adaptado para o português brasileiro para desenvolver processamento auditivo e consciência fonológica em alunos de oito a doze anos. Sua amostra incluía alunos com dislexia e alunos com desenvolvimento típico considerados bons leitores. Os grupos experimental e controle tinham dez crianças cada, cinco delas diagnosticadas com dislexia e as demais com desenvolvimento típico. Os alunos foram avaliados por meio de testes aplicados antes e depois da intervenção, que consistiu em 13 sessões de 40 minutos ministradas duas vezes por semana. Inicialmente, o grupo de alunos com dislexia apresentou resultados significativamente menores para as duas habilidades avaliadas. No pós-teste, verificouse que os alunos disléxicos e bons leitores que sofreram a intervenção foram igualmente beneficiados pelo uso do software. Os autores interpretaram os resultados como evidências da eficácia do procedimento.

No trabalho de Oliveira, Lukasova e Macedo (2010), o software Alfabetização Fônica Computadorizada, previamente utilizado com o público com deficiência intelectual (Oliveira et al., 2015) foi aplicado a dez alunos com diagnóstico de dislexia, média etária de 11 anos. Outros dez alunos, pareados de acordo com sexo, idade e série escolar, foram avaliados e serviram como grupo controle. Todos os estudantes realizaram Prova de Consciência Fonológica 
Computadorizada e por meio de cinco testes da Bale Computadorizada (Macedo et al., 2005). Os resultados demonstraram melhoras significativas nas habilidades metalinguísticas para o grupo experimental, sem aumento no tempo total de realização do teste, indicando que a decodificação se tornou mais automática para esses alunos. Estes resultados, entretanto, ainda foram menores do que a média verificada em alunos com desenvolvimento típico. No caso da escrita, houve diminuição do tempo total necessário para realização da prova.

\subsubsection{Outros públicos com Transtornos do Neurodesenvolvimento}

Três estudos focalizaram outros Transtornos do Neurodesenvolvimento: Transtorno de Aprendizagem não especificado; Transtorno de Comunicação - Gagueira e Transtorno de Déficit de Atenção e Hiperatividade (TDAH).

Verdu e de Oliveira (2014) verificaram os efeitos de um programa de intervenção computadorizado que visava ensinar leitura e escrita por meio de tarefas de seleção e cópia (de Souza et al., 2009) para um adolescente com dificuldade de aprendizagem. O software utilizado foi o mesmo empregado nos trabalhos de Menotti et al. (2019) e Benitez e Domeniconi (2018), embora, nesses trabalhos, o programa de ensino tenha sido adaptado para as populações com DI e TEA. O trabalho de Verdu e de Oliveira envolveu a realização de testes iniciais detalhados e a construção de um processo de ensino específico para as dificuldades em escrita do aluno. Ao final do processo, o aluno passou a ser capaz de escrever com proficiência palavras dissílabas e trissílabas simples.

Trabalhando com alunos com Transtorno de Comunicação do tipo gagueira, o estudo de Buzzeti et colaboradores (2016) teve como objetivo comparar os efeitos imediatos do atraso na retroalimentação auditiva na tarefa de leitura. Os autores consideraram que esse procedimento poderia ser desenvolvido com tecnologias que são facilmente acessíveis: o software Fono Tools, em conjunto com o Adaptador Andrea PureAudio USB-AS e um microfone auricular Karsect HT2. Estes equipamentos foram utilizados para provocar o efeito da Retroalimentação Auditiva Atrasada (RAA) e gravar a fala. Participaram do estudo 16 alunos de 8 a 17 anos, 11 meninos e 5 meninas, distribuídos em dois grupos. No grupo 1, havia apenas participantes com gagueira moderada, e grupo 2, com gagueira grave e muito grave. Todos os alunos realizaram avaliação audiológica, avaliação da fluência na fala espontânea e avaliação da fluência na leitura oral em duas condições de escuta: com Retroalimentação Auditiva Habitual - RAH e atrasada - RAA. Os resultados indicaram que a retroalimentação auditiva atrasada ocasionou redução das disfluências típicas da gagueira para ambos os grupos, porém a frequência de outras disfluências aumentou no grupo de gagueira moderada. Especificamente sobre a leitura, o RAA promoveu fluência da leitura, o aumento dos fluxos de sílabas e de palavras fluentes por minuto para o grupo de gagueira grave. O mesmo efeito não foi observado no grupo de gagueira moderada.

O trabalho de Pisacco et al. (2018) comparou o efeito de duas intervenções metacognitivas na escrita, memória de trabalho e nos sintomas comportamentais do TDAH. Participaram 47 alunos do quinto ao nono ano de duas escolas públicas, com média de idade de 13 anos, 34 meninos e 15 meninas. Esses alunos foram avaliados antes, imediatamente depois e 3 meses após o fim da intervenção. As avaliações incluíram dois subtestes: dígitos e sequência de números do WISC IV (Wechsler, 2013). Também foram utilizados o Rey Auditory Verbal Learning Test (RAVLT) traduzido para o português (Malloy-Diniz, Fuentes, Abrantes, Lasmar, \& Salgado, 2010), o Balanced Dictation Test (Moojen, 2011) e Narrative Text Production Task 4 (NTPT4).

A intervenção teve dois componentes, um visou melhorar a memória de trabalho por meio do software Working Memory Program (WMP- Nunes et al., 2014). Este software consiste de três jogos online e cinco jogos com multimídia gravada, com sete níveis de dificuldade (http://www.education.ox.-ac.uk/ndcs). Adicionalmente, foi utilizado o software Trabalhando com Habilidades de Organização de Textos Harmônicos (THOTH), traduzido para o português. 
Este software trabalha estratégias de memorização de código, questões orientadoras e esquemas orientadores. Os alunos realizaram 23 sessões de 40 a 50 minutos. Nas primeiras 11 sessões, os dois grupos trabalharam com o WMP. Nas demais, metade dos participantes trabalhou com ambos os softwares e metade manteve-se apenas utilizando com o WMP. Na comparação entre o grupo que recebeu apenas um dos tratamentos com o que recebeu uma combinação de ambos, os resultados indicaram que a intervenção conjunta ocasionou melhores desempenhos. Os autores concluíram que as características da escrita de narrativa que indicam organização do texto foram afetadas pelo trabalho com habilidades cognitivas (Pisacco et al, 2018).

\subsection{Tecnologias educacionais, habilidades para o letramento e instrumentos para o ensino}

Conforme se observa na Tabela 3, a tecnologia educacional utilizada variou significativamente. As três mais utilizadas, com 3 estudos $(17,6 \%)$ cada, foram: comunicação alternativa, equivalência de estímulos e a perspectiva fônica. As demais tecnologias educacionais, foram investigadas em apenas um trabalho cada.

Tabela 6: Distribuição percentual dos trabalhos por tecnologia educacional.

\begin{tabular}{|c|c|c|}
\hline Tecnologia educacional & Trabalhos & Porcentagem \\
\hline Comunicação alternativa & $\begin{array}{c}\text { Ribeiro et al. (2013); Nunes e Walter (2014); Rosa, } \\
\text { Silva e Aymone (2018) }\end{array}$ & $17,6 \%$ \\
\hline Equivalência de estímulos & $\begin{array}{l}\text { Verdu e de Oliveira (2014); Benitez e Domeniconi } \\
\text { (2018); Menotti, Domeniconi e Benitez (2019) }\end{array}$ & $17,6 \%$ \\
\hline Perspectiva fônica & $\begin{array}{l}\text { Germano e Capellini (2008); Oliveira, Lukasova e } \\
\text { Macedo (2010); Oliveira et al. (2015) }\end{array}$ & $17,6 \%$ \\
\hline $\begin{array}{l}\text { Construção de narrativas } \\
\text { visuais }\end{array}$ & Bittencourt e Fumes (2017) & $5,9 \%$ \\
\hline $\begin{array}{l}\text { Desenvolvimento de } \\
\text { estratégia auto-regulada }\end{array}$ & Pisacco et al. (2018) & $5,9 \%$ \\
\hline Diversas & Magaton e Bim (2017) & $5,9 \%$ \\
\hline $\begin{array}{l}\text { Feedback sobre articulação } \\
\text { de fonemas }\end{array}$ & Martins et al. (2016) & $5,9 \%$ \\
\hline $\begin{array}{l}\text { Prática instrucional em seu } \\
\text { próprio ritmo }\end{array}$ & de Santana, Guimarães e Mattos (2016) & $5,9 \%$ \\
\hline $\begin{array}{l}\text { Retroalimentação auditiva } \\
\text { atrasada }\end{array}$ & Buzzeti et al. (2016) & $5,9 \%$ \\
\hline $\begin{array}{l}\text { Soletração do nome do item } \\
\text { na figura }\end{array}$ & Guerra e Furtado (2013) & $5,9 \%$ \\
\hline Textos para leitura oral & Zavaleta et al. (2018) & 10 \\
\hline
\end{tabular}

No que se refere às habilidades que são componentes para o letramento, os trabalhos geralmente enfocaram mais de uma habilidade. Nos três estudos que se basearam em equivalência de estímulos (Verdu \& de Oliveira, 2012; Menotti et al., 2019; Benitez \& Domeniconi, 2018), 
uma estratégia de ensino bastante investigada em uma área conhecida como Análise Aplicada do Comportamento (Cooper, Heron, \& Heward, 2007), o foco foi nas habilidades de nomeação automática rápida de letras; nomeação automática rápida de figuras de objetos; processamento visual. Nestes estudos, o instrumento utilizado foi o software ProgLeit (Rosa Filho et al., 1998) com versões adaptadas do currículo informatizado denominado Aprendendo a Ler e Escrever em Pequenos Passos (de Souza et al., 2009). Este currículo ensina palavras simples dissílabas e trissílabas, usando tarefas de seleção envolvendo palavras impressas, figuras e palavras ditadas, além de escrita a partir das letras ou das sílabas da palavra. Um aspecto importante do programa é que ele avalia as habilidades de forma sistemática e contínua, de forma que o aluno só passa a uma nova fase de ensino após ter dominado a fase anterior.

Ainda com foco em habilidades relacionadas à leitura e escrita, três estudos trabalharam com programas relacionados à perspectiva Fônica (Germano \& Capellini, 2008; Oliveira et al., 2010; Oliveira, Saddy et al., 2015). As habilidades que foram alvo de intervenção nestes estudos, entretanto, foram diferentes. Eles enfocaram em processamento visual; memória fonológica; nomeação automática rápida de figuras de objetos. Germano e Capellini (2008) utilizaram o software Play on - Jeu d'entraînement à la lecture, adaptado para o português brasileiro. As atividades desenvolvidas incluíram discriminação de fonemas em logatomos, palavras e frases, deleção de fonemas em logatomos, palavras dissílabas e trissílabas. Os fonemas trabalhados foram estabelecidos conforme a ordem do desenvolvimento da fala e da linguagem. Oliveira et al. (2010) e Oliveira et al. (2015) utilizam o software Alfabetização Fônica Computadorizada. Esta ferramenta conta com dois grandes grupos de atividades: a) consciência fonológica, com as atividades envolvendo palavras, rimas, aliterações, sílabas e fonemas e b) alfabeto, que trabalha correspondências entre grafemas e fonemas para vogais, consoantes a apresenta atividades envolvendo encontrar e identificar palavras (Dias, 2006).

Com ênfase na comunicação e, portanto, nas habilidades de linguagem oral, processamento visual, quatro estudos fizeram uso de softwares (Ribeiro et al., 2013; Nunes \& Walter, 2014; Bittencourt \& Fumes, 2017; Rosa et al., 2018). Nestes trabalhos, os softwares foram utilizados com três finalidades: a) facilitar a criação e confecção de materiais físicos (figuras) para comunicação e aprendizagem, b) enriquecer a comunicação através da mediação da realidade aumentada e c) promover a cooperação por meio da comunicação. Para a primeira finalidade, os softwares Intellytools, Boardmaker with Speaking Dinamically Pro e Escrevendo com Símbolos foram empregados (Nunes \& Walter, 2014), além do SCALA (Bittencourt \& Fumes, 2017), que tem como objetivo apoiar a comunicação e o letramento de pessoas com autismo (Bez et al., 2013). Para a segunda finalidade, Rosa et al. (2018) utilizaram o software Autodesk 3DS Max para modelar as figuras e animações. Estes elementos foram então inseridos no software gratuito Eurasma, que permite desenvolver ações usando realidade aumentada. A terceira finalidade na comunicação (Ribeiro et al., 2013) contou com o uso do jogo ComFiM apresenta um cenário de fazenda no qual alguns objetos são disponibilizados para realização de tarefas, incluindo ferramentas, regador, escada, etc. Na primeira fase, o usuário interage com um tutor e deve solicitar ou oferecer objetos para a consecução das tarefas. No segundo nível, ele interage com um colega com o mesmo objetivo. A terceira fase exige que os dois usuários realizem a mesma tarefa para que ela seja concluída.

Dois outros estudos investigaram o uso de softwares específicos para gerenciar o processo de avaliação de alunos na identificação da dislexia (Martins et al., 2016; Zavaleta et al., 2018) e, portanto, tiveram foco nas habilidades relacionadas à memória fonológica, conhecimentos a respeito da linguagem escrita e na linguagem oral. Martins et al. (2016) desenvolveram um aplicativo que pudesse ser utilizado em dispositivos móveis e permitisse a prática de leitura pelos usuários. As respostas, bem como sua latência (tempo entre a apresentação do estímulo e a ocorrência da resposta) ficariam registrados e esses dados poderiam ser utilizados para facilitar o 
diagnóstico de dislexia. Há uma fase inicial de reconhecimento de voz e, posteriormente, são apresentadas palavras para ler. Estas palavras foram selecionadas por especialistas e apresentam nível crescente de dificuldade. O protótipo foi calibrado inicialmente com usuários adultos e sem nenhum diagnóstico de Transtornos do Neurodesenvolvimento. Zavaleta et al. (2018) empregaram um processo bastante similar, no qual os usuários deveriam ler textos simples. $\mathrm{O}$ software registra, além da correção das palavras utilizadas, a velocidade da leitura medida em palavras por minuto. Denominado de DysDTool $+L$, este software usa a abordagem RtI (Resposta à Intervenção), ou seja, a avaliação não se baseia no parâmetro de corretude em situação de teste, mas no processo de aquisição em situação de aprendizagem.

Diferente dos trabalhos descritos anteriormente, dois estudos empregaram estratégias que visavam o desenvolvimento de habilidades mais diversas, não exclusivamente relacionadas ao letramento. O trabalho de Guerra e Furtado (2013) descreve atividades que visam desenvolver habilidade de conhecimento sobre o alfabeto, memória fonológica, conhecimentos a respeito da linguagem escrita, linguagem oral e processamento visual. $\mathrm{O}$ instrumento para o ensino é um website que permite o cadastro de crianças e atividades, estabelecendo uma agenda de tarefas. Estas tarefas incluem múltiplos jogos apresentados via smartphone que usam reconhecimento de voz e de movimento.

O trabalho de Magaton e Bim (2017), de forma semelhante, acompanhou o uso de vários aplicativos para tablet em contexto educacional. Estes aplicativos tinham diversas atividades, desde algumas muito simples de identificação de cores e formas geométricas até escrita de palavras simples. O foco foi, portanto, em habilidades de processamento visual, memória fonológica e conhecimento sobre o alfabeto. Os autores realizaram uma análise descritiva de aspectos da usabilidade dos aplicativos, como facilidade de compreender o mecanismo de funcionamento, necessidade de ajuda de terceiros, ocorrência de respostas vocais, motoras e visuais durante o uso do aplicativo, entre outros. $\mathrm{O}$ aplicativo Color Monster (http://wombiapps.com/apps/color-monster-learn-thecolors/) visava ensinar a identificação de cores. Da mesma forma, TP-Shapes (http://www.technolio.com.br/app/), permitia a identificação de formas geométricas. Seasons (http://www.cleverkiddoapps.com/seasons), por sua vez, identificar formas, peças de roupa e outros. O Aiello (http://www.jogoseducacionais.com/) permite relacionar palavras a figuras. E, no aplicativo $A B C$ Palavras (http://www.technolio.com.br/app/), o aluno pode escrever o nome de figuras a partir de suas letras, que são apresentadas embaralhadas. Com o 123 Color, o aluno pode colorir a figura a partir de números. O Doodlecast (https://sagomini.com/apps/detail/doodlecast/) permite completar um desenho ou fazer um desenho livre. Finalmente, o Number sequence (https://itunes.apple.com/br/app/number-sequence-autismseries/id555257138?mt=8) trabalha o sequenciamento numérico.

O trabalho de de Santana e colabores (2016) descreve um programa que visava o treinamento profissional de jovens e adultos com deficiência intelectual. O processo centrava-se na atividade de digitação de informações em um editor de texto, tendo como foco as habilidades de nomeação automática rápida de figuras de objetos, escrita do próprio nome e conhecimentos a respeito da linguagem escrita. As informações apresentavam diferentes níveis de complexidade e estavam disponibilizadas em papel para serem copiadas pelos alunos. Em alguns casos, foram utilizados recursos para garantir a cópia sistemática de todas as letras, como "máscaras" que deslizavam permitindo a visualização de uma letra por vez. Os autores descreveram as estratégias para trabalhar com alunos com diferentes graus de habilidade em contextos de ensino coletivo.

No único estudo com foco em pessoas com Transtorno da Comunicação, Buzzeti et al. (2016) avaliou os efeitos de um software específico sobre a gagueira. As habilidades afetadas pela intervenção foram processamento visual de palavras escritas e a memória fonológica. O software Fono Tools permitiu a utilização do método de retroalimentação auditiva, no qual a pessoa ouve 
sua própria voz com um atraso de tempo ajustável pelo pesquisador. Esse recurso mantém o estímulo presente por mais tempo e pode auxiliar no desenvolvimento de fluência.

\subsection{Meios de aplicação das tecnologias}

Conforme se observa na Tabela 7, computadores foram um meio de aplicação da tecnologia em $70,6 \%$ dos estudos, ainda que não exclusivamente. Em todos os casos, o uso do computador pelo estudante ocorreu individualmente, mas com o acompanhamento de um tutor (professor ou outro profissional) ao longo das sessões.

De forma complementar, alguns estudos relataram o uso de acessórios ou recursos auxiliares. Nunes e Walter (2014), pode exemplo, usaram teclados com colmeia e impressoras para fazer fichas de comunicação. Buzzeti et al. (2015) usaram uma câmera filmadora para oferecer feedback na fala dos participantes com gagueira.

Tabela 7: Distribuição percentual dos estudos por meio de aplicação das tecnologias.

\begin{tabular}{|c|c|c|}
\hline Meio de aplicação & Trabalhos & Porcentagem \\
\hline Computador & $\begin{array}{l}\text { Bittencourt e Fumes (2017); Pisacco et al. (2018); Verdu e de } \\
\text { Oliveira (2014); Benitez e Domeniconi (2018); Menotti, } \\
\text { Domeniconi e Benitez (2019); Germano e Capellini (2008); } \\
\text { Oliveira, Lukasova e Macedo (2010); Oliveira et al. (2015); de } \\
\text { Santana, Guimarães e Mattos (2016); Buzzeti et al. (2016); } \\
\text { Guerra e Furtado (2013); Zavaleta et al. (2018) }\end{array}$ & $70,6 \%$ \\
\hline Tablet & $\begin{array}{l}\text { Ribeiro et al. (2013); Magaton e Bim (2017); Martins et al. } \\
\text { (2016) }\end{array}$ & $17,6 \%$ \\
\hline Celular & $\begin{array}{c}\text { Rosa, Silva e Aymone (2018); Martins et al. (2016); Guerra e } \\
\text { Furtado (2013) }\end{array}$ & $17,6 \%$ \\
\hline Televisão & Ribeiro et al. (2013) & $5,9 \%$ \\
\hline $\begin{array}{l}\text { Pranchas de } \\
\text { comunicação }\end{array}$ & Nunes e Walter (2014) & $5,9 \%$ \\
\hline
\end{tabular}

Em segundo lugar, como meios de aplicação mais frequentes estão os tablets e os celulares, com 17,6\% cada. Em alguns casos, o dispositivo foi utilizado como meio exclusivo de aplicação (ex. Magaton \& Bim, 2017; Rosa, Silva \& Aymone, 2018), e em outros de modo intercambiável com outros aparelhos (ex. Martins et al., 2016; Bittencourt \& Fumes, 2017).

\subsection{Tipos de estudo}

Entre os trabalhos analisados foram encontrados cinco tipos de estudos diferentes, como apresentado na Tabela 8. Foram identificados três estudos experimentais $(17,6 \%)$ que utilizaram um delineamento de grupo com grupo controle; quatro estudos experimentais $(23,5 \%)$ que compararam o desempenho de grupos de participantes, mas não contaram com grupo controle, também chamados de quase-experimentos; um estudo (5,9\%) que utilizou delineamento de sujeito único; sete trabalhos $(41,2 \%)$ que foram classificados como estudos de caso; e dois $(11,8 \%)$ que foram relatos de experiências. 
Tabela 8: Distribuição percentual dos estudos por tipo de estudo.

\begin{tabular}{ccc}
\hline Tipo de estudo & Trabalhos & Porcentagem \\
\hline $\begin{array}{c}\text { Experimental com } \\
\text { grupo controle }\end{array}$ & $\begin{array}{c}\text { Benitez e Domeniconi (2018); Germano e Capellini (2008); } \\
\text { Oliveira, Lukasova e Macedo (2010) }\end{array}$ & $17,6 \%$ \\
$\begin{array}{c}\text { Experimental sem } \\
\text { grupo controle }\end{array}$ & Pisacco et al. (2018); Oliveira et al. (2015); Buzzeti et al. & $23,5 \%$ \\
(2016); Zavaleta et al. (2018) & Menotti, Domeniconi e Benitez (2019) \\
Delineamento de & Ribeiro et al. (2013); Rosa, Silva e Aymone (2018); & $5,9 \%$ \\
Estudo de caso & Bittencourt e Fumes (2017); Magaton e Bim (2017); Martins & $41,2 \%$ \\
et al. (2016); Guerra e Furtado (2013); Verdu e de Oliveira & $(2014)$ \\
Relato de experiência & Nunes e Walter (2014); de Santana, Guimarães e Mattos & $(2016)$ \\
\hline
\end{tabular}

\subsection{Custos do uso das tecnologias}

Os estudos não informaram os custos para a obtenção da licença de uso dos softwares nos casos em que eles eram proprietários. Em alguns trabalhos os softwares eram gratuitos e de uso livre, como é o caso do SCALA (Bittencourt \& Fumes, 2017) e do GCOMPRIS, utilizado como software de apoio por de Santana, Guimarães e Mattos (2016).

Os custos relativos aos meios de aplicação da tecnologia, também não foram especificados nos trabalhos. A falta de detalhamento quanto ao número de equipamentos e os modelos de computadores, tablets e celulares utilizados impediu um cálculo do custo para sua obtenção.

\section{Discussão}

O presente estudo encontrou 17 trabalhos que utilizaram tecnologias educacionais para letramento e alfabetização de estudantes com Transtornos do Neurodesenvolvimento no contexto brasileiro. Os diagnósticos mais comuns dos participantes destes estudos foram TDAH, Dislexia e TEA, respectivamente. A faixa etária mais frequente foi entre os 11 e 13 anos de idade. As tecnologias educacionais mais investigadas foram relacionadas à leitura e escrita, sob duas perspectivas distintas, a equivalência de estímulos e a fônica. A comunicação alterativa também foi uma tecnologia frequentemente presente nos estudos. Como meio de aplicação das tecnologias, o computador foi o mais utilizado, seguido pelos tablets e celulares em segundo lugar. Apesar de alguns trabalhos terem utilizado delineamentos de grupo (com e sem grupo controle), a maioria deles consistiu em estudos de caso. O custo do uso das tecnologias não foi possível de analisar em função da falta de informações nos trabalhos analisados.

Na década de 1990, segundo Wehmeyer, Smith, Palmer e Davies (2004), a tecnologia já estava sendo amplamente utilizada na educação - dentro e fora do ambiente escolar - entretanto, pessoas com deficiência raramente tinham acesso a esses recursos. Os autores identificaram que, naquele momento, os principais obstáculos ao uso dos equipamentos eram a falta de treinamento dos alunos e professores e, adicionalmente, a ausência de adaptações ou programas específicos para as necessidades desses indivíduos.

Desde então, o uso da tecnologia tem se tornado muito mais presente no cotidiano das pessoas, de modo que as novas gerações têm sido expostas desde muito jovens (Ahearne et al., 
2016). Entretanto, os desafios para o uso de tecnologia no contexto escolar se mantêm, com relatos constantes sobre falta de infraestrutura e de treinamento de professores (Chew, Cheng, Kinshuk, $\&$ Chen, 2018). Adicionalmente, as adaptações para as populações com necessidades especiais ainda não são frequentes e, mesmo quando ocorrem, geralmente não são devidamente testadas.

O número reduzido de trabalhos encontrados na presente revisão e a qualidade da evidência neles produzida é semelhante ao encontrado em outras revisões da área e demonstram o quanto estudos com alta qualidade ainda são escassos (eg. da Silva et al., 2020; Ferreira et al., 2018; Khan et al., 2019). Os estudos de caso e os relatos de experiência encontrados na presente revisão somaram 53\%. Este percentual elevado dos dois tipos de trabalho evidencia que há interesse por parte de pesquisadores e educadores na adoção de recursos tecnológicos para o ensino de indivíduos com Transtornos do Neurodesenvolvimento, no entanto, revelam também que a realização de estudos quantitativos que produzam evidências da eficácia destes recursos não segue o mesmo passo.

Em outra revisão sistemática, Valencia, Rusu, Quiñones e Jamet (2019) realizaram uma busca por trabalhos que permitissem avaliar os impactos da tecnologia sobre a aprendizagem de indivíduos com TEA. Os 94 trabalhos encontrados pelos autores indicaram uma tendência crescente na produção desse tipo de estudo nos últimos dez anos. No entanto, a distribuição percentual por tipo de trabalho seguiu a mesma tendência da presente revisão. Dos trabalhos analisados por Valencia et al. $74 \%$ foram estudos de caso e $13,8 \%$ foram revisões de literatura, restando somente $11,7 \%$ de dados empíricos. Os trabalhos encontrados por Valencia et al. envolvem softwares, uso de gadgets como celulares e tablets, mas também tecnologias menos usuais, como realidade virtual, realidade aumentada, agentes virtuais, sensores e geolocalização. Entre as habilidades ensinadas, verificou-se um foco em linguagem, uso do dinheiro, identificação de cores, conceitos de matemática, programação e ciência. Além disso, houve tecnologias que buscavam ajudar a desenvolver habilidades práticas como autocuidado, atividades de vida diária e transporte, além de habilidades sociais, incluindo comunicação, emoção e relacionamentos interpessoais. Valencia et al. verificaram que, de modo geral, os aplicativos foram efetivos para ensinar e a experiência era apreciada pelos usuários.

É interessante notar que entre os trabalhos encontrados na presente revisão, aqueles cujos métodos foram de maior qualidade, avaliada pelo tipo de delineamento adotado, foram também os que adotaram tecnologias educacionais solidamente fundamentadas. Destacam-se, portanto, os estudos sobre perspectiva fônica, equivalência de estímulos, retroalimentação auditiva e intervenções metacognitivas. Assim, educadores que queiram utilizar tecnologias educacionais com seus alunos devem estar atentos ao conhecimento subjacente à tecnologia desenvolvida e, portanto, dar preferências aos recursos que estejam neles embasados.

Em relação ao perfil da população, a presente revisão encontrou trabalhos nos quais participaram pessoas com Transtornos do Neurodesenvolvimento diversos, de faixas etárias diferentes, semelhante ao encontrado por Khan et al. (2019). Este resultado sugere que as tecnologias que têm sido desenvolvidas e testadas no contexto brasileiro visando desenvolver habilidades relacionadas à alfabetização e ao letramento não têm se concentrado em indivíduos com diagnósticos específicos de uma faixa etária apenas. Os trabalhos realizados com crianças mais jovens, entre os 5 e os 7 anos de idade, geralmente se concentraram no desenvolvimento de habilidade de comunicação e eram com crianças com TEA (e.g., Ribeiro et al. 2013; Rosa et al., 2018). Este resultado não é de nenhuma maneira surpreendente, uma vez que déficits na comunicação estão entre as características centrais do TEA (APA, 2013) e que, se nenhuma intervenção for realizada para remediar tais déficits, muitas crianças com este diagnóstico não desenvolverão comunicação oral (Anderson et al., 2007).

$\mathrm{Na}$ faixa etária com o maior número de participantes, entre 11 e 13 anos, os diagnósticos foram mais variados (Dislexia, TDAH, Transtornos da Comunicação e TEA) e as tecnologias 
educações investigadas geralmente visaram a identificação de déficits relacionados à leitura (especialmente com a população com dislexia) ou o desenvolvimento de habilidades que melhorassem o desempenho na leitura e na escrita (e.g., Pisacco et al., 2018). Este resultado sugere que mais participantes estiveram em estudos de caráter remediativo, ou seja, quando uma dificuldade já foi ou está sendo identificada e se pretende contorná-la, do que em estudos com caráter preventivo. Além disso, isso indica que a remediação tem ocorrido tardiamente, uma vez que no Brasil a alfabetização deve ocorrer antes dos 8 anos de idade, segundo o Plano Nacional de Educação (lei 13.005/2014), com orientações mais recentes para que ocorra ainda antes (decreto $\mathrm{n}^{\mathrm{o}}$ 9.765, de 11 de abril de 2019).

Nesta revisão, também foi possível notar que as tecnologias educacionais foram utilizadas de forma heterogênea entre as populações, indicando necessidades distintas de habilidades relacionadas ao letramento a serem desenvolvidas. Para os alunos com DI, por exemplo, uma variedade maior de tecnologias foi utilizada, como a comunicação alternativa, prática instrucional em seu próprio ritmo (com indivíduos adultos visando inserção no mercado de trabalho), alfabetização na perspectiva fônica e equivalência de estímulos. Consequentemente, a gama de habilidades que foram alvo dos estudos também foi mais ampla.

Para os alunos com dislexia, por outro lado, a variação de tecnologias educacionais foi menor e esteve sempre relacionada à linguagem oral e à memória fonológica. Este resultado indica que, apesar da importância em reconhecer as deficiências e potencialidades de cada aluno individualmente, as necessidades educacionais podem ser mais ou menos específicas a depender da população da qual ele faz parte.

Em relação às habilidades ensinadas, as tecnologias podem ser divididas em dois grandes grupos: (a) de comunicação, geralmente manipulam figuras, fotos ou vídeos para transmitir mensagens, podendo ser utilizadas via computador, tablet ou celular. São utilizadas com alunos com Transtorno do Espectro Autista (TEA) e/ou alunos com Deficiência Intelectual (DI). (b) habilidades de leitura e escrita, que apresentam uma sequência sistemática de atividades visando trabalhar diferentes aspectos do processo de alfabetização. No segundo caso, o público mais frequente foram os alunos com Dislexia.

Outra contribuição da presente revisão foi a identificação dos meios pelos quais a tecnologia vem sendo aplicada. O computador foi o meio de aplicação utilizado na grande maioria dos trabalhos (70,6\%), seguido por tablets $(17,6 \%)$ e smartphones $(17,6 \%)$. Apesar disso, o meio de aplicação não apareceu como um determinante de grande relevância para a efetividade das tecnologias, mas deve ser considerado na medida que impacta nos custos e na logística das aplicações.

Revisões de estudos com objetivos semelhantes também têm encontrado o uso de meios variados para a aplicação da tecnologia. Cidrim e Madeiro (2017), por exemplo, em uma revisão bibliográfica integrativa do uso de tecnologias da informação e comunicação com pessoas com Dislexia, verificaram o uso de computador, tablets, celulares e e-readers como meios para interagir com os softwares que provinham a intervenção. De modo mais específico, Reid, Strnadová e Cumming (2013) realizaram revisão sobre a utilização de tecnologias móveis, incluindo smartphones, iPod, tablets e laptops para auxiliar alunos com Dislexia. No entanto, nenhuma das duas revisões analisou quantitativamente a distribuição dos estudos conforme o meio de aplicação de forma que permita uma comparação com os achados do presente trabalho.

O uso frequente de computadores como meio de aplicação verificado pela presente revisão, apesar das diversas conveniências oferecidas por tablets e smartphones, tais como, melhor portabilidade, usabilidade e até menor custo, em alguns casos, talvez reflita uma realidade do contexto educacional brasileiro mais do que uma tendência geral no ensino de pessoas com Transtornos do Neurodesenvolvimento. Na revisão sistemática de Valentine et al. (2020), os 
estudos encontrados foram produzidos nos Estados Unidos e na Europa e as tecnologias estiveram muito menos centradas no uso do computador e foram mais variadas, incluindo o uso de robôs e de realidade virtual. A comparação entre a presente revisão e a revisão conduzida por Valentine et al. deve ser feita com cuidado, pois no estudo de Valentine et al. foram excluídos estudos cujo foco não fosse o uso clínico da tecnologia, como o uso em contextos educacionais ou que visavam inserção no mercado de trabalho.

Importante observar, entretanto, que em todos os casos a aplicação de tecnologias requer infraestrutura e recursos humanos no contexto escolar. Isto é, são necessário equipamentos e treinamento dos profissionais. Em alguns dos estudos, os softwares realizavam tarefas simples, como seleção e impressão de figuras para pranchas de comunicação (e.g., Nunes \& Walter, 2014); o trabalho do professor ao utilizar essa funcionalidade foi o que gerou o resultado pedagógico.

Na presente revisão, foi encontrado apenas um estudo no qual participaram pessoas com TDAH, exclusivamente. Esse resultado é, em parte, surpreendente, porque a prevalência de TDAH em crianças em idade escolar no Brasil está estimada entre 5\% a 6,7\% (Poeta \& Rosa Neto, 2004; Ponde \& Freire, 2007), e estima-se que 14\% também manifestem dificuldades de aprendizagem em leitura e escrita (de Paula \& Navas, 2018). Ao descrever as dificuldades na aprendizagem de leitura e escrita de alunos com TDAH, de Paula e Navas (2018) verificaram que esses alunos apresentam resultados piores que seus pares com desenvolvimento típico, mesmo para indivíduos que não tem transtorno de dificuldade associado. Essa dificuldade se manifesta na performance de leitura, escrita e também em atividades de consciência fonológica. Segundo DuPaul e Langberg (2015), as diferenças no desempenho escolar de crianças com TDAH em relação a seus pares típicos são maiores em habilidades de leitura e escrita do que em outras, como matemática e soletração, por exemplo. A escassez de pesquisas com este público, evidenciada pela presente revisão, enfatiza a importância do desenvolvimento de soluções específicas, e os recursos tecnológicos podem ser um aliado nisso. O trabalho de Pisacco et al. (2018), o único exclusivamente com crianças com TDAH, parece estar alinhado com esta visão, na medida em que implementou processos de intervenção focalizando habilidades cognitivas e verificou resultados no processo de aprendizagem de leitura e escrita.

Com relação aos transtornos de comunicação, Almerini (2014) observa que as habilidades de expressão representam uma dimensão fundamental no desenvolvimento do indivíduo, na medida em que permitem a comunicação de necessidades e a participação ativa nos processos sociais e educacionais. Em geral, quando os alunos melhoram suas habilidades de comunicação, a incidência de comportamentos agressivos, de birra e recusas diminui. Isso ocorre porque esses comportamentos são, muitas vezes, uma resposta à frustração, ansiedades ou estímulos que são percebidos como ameaçadores ou aversivos.

Apesar disso, na presente revisão, apenas um estudo destinado à população com Transtornos de Comunicação foi encontrado, relatando a utilização de retroalimentação habitual e atrasada para alunos com gagueira. Nessa intervenção, o uso da tecnologia que capta e reproduz a resposta dos alunos é central. Buzzeti et al. (2016) observou que essa tecnologia apresenta melhores resultados para a população com gagueira grave e muito grave. Seu efeito no processo de letramento é mediado pela redução dos sintomas típicos da gagueira.

No presente trabalho, o transtorno do desenvolvimento da coordenação motora foi o único entre os Transtornos do Neurodesenvolvimento para o qual nenhum estudo foi encontrado, ainda que sua prevalência estimada no Brasil seja de 7,1\% entre escolares de 7 a 10 anos de idade (Beltrame, 2017). No caso da leitura e da escrita, os transtornos relacionados ao movimento afetam principalmente as atividades que requerem coordenação motora fina, como desenhar, recortar e escrever (Ohl et al., 2013). Também podem implicar em dificuldade na coordenação viso-motora, afetando, por exemplo, a habilidade de cópia e a escrita. Caso afetem a pronúncia, 
podem exercer impacto na leitura. Apesar disso, não foram encontrados trabalhos destinados a essa população na presente revisão.

Pulzi e Rodrigues (2015) chamam atenção para o fato de que crianças com transtorno de desenvolvimento da coordenação frequentemente apresentam comorbidade com TEA, TDAH, deficiência intelectual e dificuldades de aprendizagem. Esse aspecto torna mais relevante o estudo combinado do efeito de diferentes procedimentos nessas populações.

Conclui-se, portanto, que os resultados do presente trabalho demonstram que diversas tecnologias educacionais vêm sendo utilizadas para auxiliar no processo de letramento de alunos com Transtornos do Neurodesenvolvimento. No Brasil, estas tecnologias têm atuado em relação às seguintes dimensões: (1) auxiliam na avaliação dos casos; (2) oferecem atividades organizadas de modo sistemático; (3) permitem um percurso relativamente individualizado para cada aluno; (4) representam formas alternativas de comunicação, especialmente pela utilização de figuras e outros sinais gráficos.

Os resultados da presente revisão evidenciam três importantes desafios, dois deles intimamente relacionados e um terceiro que se relaciona ao tema de modo tangencial. Os dois primeiros são o volume e a qualidade da produção nacional na temática. Primeiramente, o número de estudos é obviamente escasso, dada a necessidade de suporte educacional para pessoas com Transtornos do Neurodesenvolvimento, as possibilidades tecnológicas disponíveis e atualmente mais acessíveis. A produção no contexto brasileiro, conforme demonstrada nesta revisão, nem mesmo cobre todos os Transtornos do Neurodesenvolvimento existentes. Além disso, muitos trabalhos encontrados apesar de apresentarem propostas interessantes, apresentaram descrições dos processos de intervenção e avaliação que foram insuficientes para uma replicação em pesquisa ou para o uso em contextos clínicos e educacionais. Este problema expõe o segundo desafio, descrever e avaliar de forma mais acurada os recursos atualmente disponíveis, com a adoção de métodos de pesquisa mais precisos, para que o uso das tecnologias seja feito nos casos em que ela realmente tornar o ensino mais eficaz e econômico, em benefício de professores, alunos e seus familiares.

O terceiro desafio está na formação de professores para o uso das tecnologias educacionais (Belloni, 1998). Este tema não foi abordado diretamente neste trabalho for estar fora do seu escopo, mas certamente é um fator que pode determinar se algum recurso tecnológico será utilizado, como será utilizado e se seu uso trará bons resultados aos alunos.

\section{Referências}

Ahearne, C., Dilworth, S., Rollings, R., Livingstone, V., Murray, D. (2016). Touch-screen technology usage in toddlers. Archives of Disease in Childhood,101, 181-183. doi: $\underline{\text { 10.1136/archdischild-2015-309278 [GS Search] }}$

Almerini, J. (2014) Planning and Implementing Interventions for Students with Communication Disorders: An Integrated Framework with Perspectives from Cognitive, Developmental, \& Behavioral Psychology, Occupational Terapy, Physical Terapy, Speech Terapy, and Linguistics, Graduate Annual: 2, Article 5. Disponível em: http://digitalcommons.lasalle.edu/graduateannual/vol2/iss1/5

American Psychiatric Association (2013) Diagnostic and Statistical Manual of Mental Disorders. Fifth Edition. Washington, DC: American Psychiatric Association Publishing.

Anderson, D. K., Lord, C., Risi, S., DiLavore, P. S., Shulman, C., Thurm, A., Welch, K., \& Pickles, A. (2007). Patterns of growth in verbal abilities among children with autism 
spectrum disorder. Journal of Consulting and Clinical Psychology, 75(4), 594. doi: $\underline{10.1037 / 0022-006 X .75 .4 .594}$ [GS Search]

Belloni, M. L. (1998). Tecnologia e formação de professores: Rumo a uma pedagogia pósmoderna?. Educação \& Sociedade, 19(65), 143-162. doi: 10.1590/S0101$\underline{73301998000400005}$ [GS Search]

Beltrame, T. S., Capistrano, R., Alexandre, J. M., Lisboa, T., Andrade, R. D., \& Felden, É. P. G. (2017). Prevalência do Transtorno do Desenvolvimento da Coordenação em uma amostra de crianças brasileiras. Cadernos Brasileiros de Terapia Ocupacional, 25(1). doi: 10.4322/01044931.ctoAO0777 [GS Search]

Benini, W., \& Castanha, A. P. (2016). A inclusão do aluno com transtorno do espectro autista na escola comum: desafios e possibilidades. Cadernos PDE 1. [GS Search]

Benitez, P., \& Domeniconi, C. (2018). Atuação do psicólogo na inclusão escolar de estudantes com autismo e deficiência intelectual. Psicologia Escolar e Educacional, 22(1), 163-172. doi: $\underline{10.1590 / 2175-35392018013926}$ [GS Search]

Bengtson, C., \& Pino, D. (2018). Inclusão e letramento para estudantes com deficiência. In A. G. Gonçalves; F. Cia; J. A. P. Campos (Ed.), Letramento para o estudante com deficiência (p. 28-39). São Carlos, SP: EdUFSCar.

Bez, M. R., Rico, A., Pereira, E., Passerino, L. (2013) Desenvolvimento de narrativas visuais no SCALA: estudo de caso de uma turma de inclusão da Educação Infantil. Informática na Educação: teoria e prática, 16(2). doi: 10.22456/1982-1654.43424 [GS Search]

Bishop, J. (2003). The Internet for educating individuals with social impairments. Journal of Computer Assisted Learning, 19(4), 546-556. doi:10.1046/j.0266-4909.2003.00057.x [GS Search]

Bittencourt, I. G. de S., \& Fumes, N. D. L. F. (2017). A tecnologia assistiva scala como recurso para produção de narrativas e registro de dados nas pesquisas em educação: Uma experiência com pessoas adultas com transtorno do espectro autista. Revista Ibero-Americana de Estudos em Educação, 12(esp.), 1481-1495. doi: 10.21723/riaee.v12.n.esp.2.1304 [GS Search]

Brasil (2015). Lei 13.146, de 6 de julho de 2015. Institui a Lei Brasileira de Inclusão das Pessoas com Deficiência (Estatuto da Pessoa com Deficiência). Diário Oficial da União 2015; 7 jul.

Buzzeti, P. B. M. de M., Fiorin, M., Martinelli, N. L., Cardoso, A. C. V., \& de Oliveira, C. M. C. (2016). Comparação da leitura de escolares com gagueira em duas condições de escuta: Habitual e atrasada. Revista CEFAC, 18(1), 67-73. doi: 10.1590/1982-0216201618114015 [GS Search]

Camanho, G. L. (2009). Editorial: nível de evidência. Revista Brasileira de Ortopedia, 44(6), 0102. doi: 10.1590/S0102-36162009000600001 [GS Search]

Chew, S. W., Cheng, I.-L., Kinshuk, \& Chen, N.-S. (2018). Exploring challenges faced by different stakeholders while implementing educational technology in classrooms through expert interviews. Journal of Computers in Education, 5(2), 175-197. doi: 10.1007/s40692$\underline{018-0102-4}$ [GS Search]

Cidrim, L., \& Madeiro, F. (2017). Tecnologias da Informação e da Comunicação (TIC) aplicadas à dislexia: revisão de literatura. Revista CEFAC, 19(1), 99-108. doi: 10.1590/1982$\underline{021620171917916}$ [GS Search]

Cooper, J. O., Heron, T. E., \& Heward, W. L. (2007). Applied behavior analysis ( $2^{\circ}$ ed). New Jersey: Pearson Education Inc. 
da Silva, J. A., de Carvalho, M. E., Caiado, R. V. R., \& Barros, I. B. R. (2020). As tecnologias digitais da informação e comunicação como mediadoras na alfabetização de pessoas com transtorno do espectro do autismo: uma revisão sistemática da literatura . Texto Livre: Linguagem E Tecnologia, 13(1), 45-64. doi: 10.17851/1983-3652.13.1.45-64 [GS Search]

de Oliveira, D. G., Lukasova, K., \& de Macedo, E. C. (2010). Avaliação de um programa computadorizado para intervenção fônica na dislexia do desenvolvimento. Psico-USF, 15(3), 277-286. doi: 10.1590/S1413-82712010000300002 [GS Search]

de Paula, E. M. S., \& Navas, A. L. (2018). Profile of reading difficulties in children with attention deficit hyperactivity disorder: a literature review. Revista CEFAC, 20(6), 785-797. doi: $\underline{10.1590 / 1982-021620182064718}$ [GS Search]

de Santana, V. F., Guimarães, R. L., \& Mattos, A. B. (2016, April). Identifying challenges and opportunities in computer-based vocational training for low-income communities of people with intellectual disabilities. In Proceedings of the 13th Web for All Conference, Montreal, Quebec, Canadá, 16 (p. 2). ACM. doi: 10.1145/2899475.2899480 [GS Search]

de Souza, D.G.; de Rose, J.C.; Domeniconi, C. (2009). Applying relational operant's to reading and spelling. In: Rehfeldt, R.A.; BarnesHolmes, Y. (Orgs.). Derived relational responding: Applications for learners with autism and other developmental disabilities (pp.173-207). Oakland, CA: New Harbinger Publications. [GS Search]

Dias, Natália Martins. (2006). Alfabetização fônica computadorizada: usando o computador para desenvolver habilidades fônicas e metafonológicas. Psicologia Escolar e Educacional, 10(1), 148-152. doi: 10.1590/S1413-85572006000100017 [GS Search]

DuPaul, G. J., \& Langberg, J. M. (2015). Educational impairments in children with ADHD. In R. A. Barkley (Ed.), Attention-deficit hyperactivity disorder: A handbook for diagnosis and treatment (p. 169-190). New York, NY: The Guilford Press.

Eunice Kennedy Shriver National Institute of Child Health and Human Development, NIH, DHHS. (2000). Report of the National Reading Panel: Teaching Children to Read: Reports of the Subgroups (00-4754). Washington, DC: U.S. Government Printing Office.

Faraone, S. V., Biederman, J., \& Mick, E. (2006). The age-dependent decline of attention deficit hyperactivity disorder: a meta-analysis of follow-up studies. Psychological medicine, 36(2), 159. doi: 10.1017/S003329170500471X [GS Search]

Ferreira, W., Cordeiro, R., Aguiar, Y. P. C., Saraiva, J., Tardif, C., \& Galy, E. (2018, October). Panorama das Publicações Nacionais sobre Autismo, Educação e Tecnologia. In Brazilian Symposium on Computers in Education (Simpósio Brasileiro de Informática na EducaçãoSBIE) (Vol. 29, No. 1, p. 913). doi: 10.5753/cbie.sbie.2018.913 [GS Search]

Galvani, M. D., \& Mendes, M. T. S. (2018). Letramento para estudantes com deficiência intelectual. In A. G. Gonçalves; F. Cia; J. A. P. Campos (Ed.), Letramento para o estudante com deficiência (p. 28-39). São Carlos, SP: EdUFSCar.

Galvão, T. F., \& Pereira, M. G. (2015). Avaliação da qualidade da evidência de revisões sistemáticas. Epidemiologia e Serviços de Saúde, 24(1), 173-175. doi: 10.5123/S1679$\underline{49742015000100}$ [GS Search]

Germano, G. D., \& Capellini, S. A. (2008). Eficácia do programa de remediação auditivo-visual computadorizado em escolares com dislexia. Pró-Fono Revista de Atualização Científica, 20(4), 237-242. doi: 10.1590/S0104-56872008000 [GS Search] 
Glaeser, L. (2015). Breaking through: Using educational technology for children with special needs. Education and Information Technologies, 21(5), 1243-1247. doi: 10.1007/s10639$\underline{015-9378-4}$

Guerra, E., \& Furtado, F. (2013). A proposal software for multidisciplinary treatment of autistic children. Proceedings of VIII Iberian Conference of Systems and Techonologies, Lisboa, Portugal, 8. [GS Search]

Khan K., Hall C.L., Davies E.B., Hollis C., Glazebrook C. (2019) The Effectiveness of WebBased Interventions Delivered to Children and Young People With Neurodevelopmental Disorders: Systematic Review and Meta-Analysis Journal of Medical Internet Research, 21. doi: $\underline{10.2196 / 13478}$ [GS Search]

King, BH. (2016) Psychiatric comorbidities in neurodevelopmental disorders. Curr Opin Neurol. 29(2):113-7. doi: 10.1097/WCO.0000000000000299 [GS Search]

Magaton, H. C., \& Bim, S. A. (2017, October). The Use of Educational Applications by Children with Autistic Spectrum Disorder - A Case of Study. Proceedings of the XVI Brazilian Symposium on Human Factors in Computing System, Joinville, SC, Brazil, 16. doi: $\underline{10.1145 / 3160504.3160520}$ [GS Search]

Malloy-Diniz, L. F., Fuentes, D., Abrantes, S. S., Lasmar, V. A., \& Salgado, J. V. (2010). Teste de aprendizagem auditivo-verbal de Rey (RAVLT). In:L. F.-D. Malloy-Diniz, D. Fuentes, O. Mattos, \& N. Abreu, Avaliação Neuropsicológica. Porto Alegre: Artmed. [GS Search]

Martins, V. F., Lima, T., Sampaio, P. N. M., \& de Paiva, M. (2016). Mobile application to support dyslexia diagnostic and reading practice. Proceedings of the XIII International Conference of Computer Systems and Applications, Agadir, Marrocos, 13. doi: 10.1109/AICCSA.2016.7945710 [GS Search]

Menotti, A. R. S., Domeniconi, C., \& Benitez, P. (2019). Atividades aplicadas pelos pais para ensinar leitura para filhos com autismo. Psicologia Escolar e Educacional. doi: $\underline{10.1590 / 2175-35392019015073}$ [GS Search]

Moher D., Liberati A., Tetzlaff J., \& Altman D. G., (2009). Preferred reporting items for systematic reviews and meta-analyses: the PRISMA statement. PLoS Med, 21;6(7). doi: $\underline{10.1371 / \text { journal.pmed.1000097 [GS Search] }}$

Moojen, S. M. (2011). A escrita ortográfica na escola e na clínica: teoria, avaliação e tratamento. São Paulo: Casa do Psicólogo.

National Early Literacy Panel. (2008). Developing early literacy: Report of the National Early Literacy Panel. Executive Summary. Washington, DC: National Institute for Literacy.

National Institute of Child Health \& Human Development. (2000). Report of the National Reading Panel: Teaching children to read: An evidence-based assessment of the scientific research literature on reading and its implications for reading instruction. (NIH Publication No. 004769). Washington, DC: U. S. Government Printing Office.

Nunes, L. R. O. P. \& Walter, C. C. F. (2014). A Comunicação Alternativa para além das Tecnologias Assistivas. Arquivos Analíticos de Políticas Educativas, 22(83), 1-15. doi: 10.14507/epaa.v22n83.2014 [GS Search]

Nunes, T., Barros, R., Evans, D., \& Burman, D. (2014). Improving deaf children's working memory through training. International Journal of Speech and Language Pathology and Audiology, 2, 51-66. doi: 10.12970/2311-1917.2014.02.02.1 [GS Search]

Ohl, A. M., Graze, H., Weber, K., Kenny, S., Salvatore, C., \& Wagreich, S. (2013). Effectiveness of a 10-week Tier-1 Response to Intervention program in improving fine motor and visual- 
motor skills in general education kindergarten students. American Journal of Occupational Therapy, 67(5), 507-514. doi: 10.5014/ajot.2013.008110 [GS Search]

Oliveira, A. T. de, Saddy, B. S., Mograbi, D. C., \& Coelho, C. L. M. (2015). Jogos eletrônicos na perspectiva da avaliação interativa: ferramenta de aprendizagem com alunos com deficiência intelectual. Neuropsicologia Latinoamericana, 7(3), 28-35. doi: 10.5579/rn1.2013.0269 [GS Search]

Pisacco, N. M. T., Sperafico, Y. L. S., Enricone, J. R. B., Guimarães, L. S. P., Rohde, L. A., \& Dorneles, B. V. (2018). Metacognitive interventions in text production and working memory in students with ADHD. Psicologia: Reflexão e Crítica, 31(5). doi: 10.1186/s41155-017$\underline{0081-9}$ [GS Search]

Poeta, L. S., \& Rosa Neto, F. (2004). Estudo epidemiológico dos sintomas do transtorno do déficit de atenção/hiperatividade e transtornos de comportamento em escolares da rede pública de Florianópolis usando a EDAH. Brazilian Journal of Psychiatry, 26(3), 150-155. doi: $\underline{10.1590 / \text { S1516-44462004000300004 [GS Search] }}$

Pondé, M. P., \& Freire, A. C. C. (2007). Prevalence of attention deficit hyperactivity disorder in schoolchildren in the city of Salvador, Bahia, Brazil. Arquivos de Neuro-Psiquiatria, 65(2A), 240-244. doi: 10.1590/S0004-282X2007000200010 [GS Search]

Pulzi, W., \& Rodrigues, G. M. (2015). Transtorno do Desenvolvimento da Coordenação: uma Revisão de Literatura. Revista Brasileira de Educação Especial, 21(3), 433-444. doi: $\underline{10.1590 / \text { S1413-65382115000300009 [GS Search] }}$

Reid, G., Strnadová, I., \& Cumming, T. (2013). Expanding horizons for students with dyslexia in the 21st century: universal design and mobile technology. Journal of Research in Special Educational Needs, 13(3), 175-181. doi: 10.1111/1471-3802.12013 [GS Search]

Ribeiro, P. C., Braz, P., Silva, G. F., \& Raposo, A. (2013, Outubro). ComFiM: Um Jogo Colaborativo para Estimular a Comunicação de Crianças com Autismo. In Proceedings of the X Brazilian Symposium in Collaborative Systems, Manaus, AM, Brasil, 13 (p. 72). Sociedade Brasileira de Computação. [GS Search]

Rosa, V. I., da Silva, R. P., \& Aymone, J. L. F. (2018). Design inclusivo: Processo de desenvolvimento de prancha de comunicação alternativa e aumentativa para crianças com transtorno do espectro do autismo utilizando realidade aumentada. Design E Tecnologia, 8(15), 51-67. doi: 10.23972/det2018iss15pp51-67 [GS Search]

Rosa Filho, A. B.; Rose, J. C. C.; Souza, D. G.; Hanna, E. S.; Fonseca, M. L. (1998). Aprendendo a ler e escrever em pequenos passos. Software de Ensino.

Soares, M. (2004). Letramento e alfabetização: as muitas facetas. Revista brasileira de educação, (25), 5-17. doi: 10.1590/S1413-24782004000100002 [GS Search]

Thapar, A., Cooper, M., \& Rutter, M. (2017). Neurodevelopmental disorders. The lancet. Psychiatry, 4(4), 339-346. doi: 10.1016/S2215-0366(16)30376-5 [GS Search]

Valencia, K.; Rusu, C.; Quiñones, D. \& Jamet, E. (2019) The Impact of Technology on People with Autism Spectrum Disorder: A Systematic Literature Review. Sensors 2019, 19(20), 4485. doi: $\underline{10.3390 / \mathrm{s} 19204485 \text { [GS Search] }}$

Valentine, A. Z., Brown, B. J., Groom, M. J., Young, E., Hollis, C., \& Hall, C. L. (2020). A systematic review evaluating the implementation of technologies to assess, monitor and treat neurodevelopmental disorders: A map of the current evidence. Clinical Psychology Review, 101870. doi: 10.1016/j.cpr.2020.101870 [GS Search] 
Verdu, A. C. M. A., \& de Oliveira, F. M. (2014). Accuracy in dictation after improvement of reading and copying skills in a student with learning difficulties. Estudos de Psicologia (Campinas), 31(1), 25-34. doi: 10.1590/0103-166X2014000100003 [GS Search]

Wechsler, D. (2013). WISC-IV: Escala de Inteligência Wechsler para Crianças: Manual. 4 ed. Adaptação Brasileira: Rueda, F J M; Noronha, A P P; Sisto, F F; Santos, A A A; Castro, N R. São Paulo: Casa do Psicólogo.

Wehmeyer, M. L., Smith, S. J., Palmer, S. B., \& Davies, D. K. (2004). Technology Use by Students with Intellectual Disabilities: An Overview. Journal of Special Education Technology, 19(4), 7-21. doi: 10.1177/016264340401900402 [GS Search]

Whitehouse, A. J., Line, E. A., Watt, H. J., \& Bishop, D. V. (2009). Qualitative aspects of developmental language impairment relate to language and literacy outcome in adulthood. International Journal of Language \& Communication Disorders, 44(4), 489-510. doi: 10.1080/13682820802708080 [GS Search]

Zavaleta, J., Cerceau, R., Sigette, E., Costa, J. R. M., da Cruz, S. M. S., Manhães, L. M. B., \& Cerceau, R. (2018). School Inclusion Using Computational Monitoring of Reading for Students with Dyslexia. Proceedings of XIII Latin American Conference on Learning Technologies, São Paulo, SP, Brasil, 13. doi: 10.1109/LACLO.2018.00052 [GS Search] 